\title{
Overview of the first HyMeX special observation period over Croatia
}

\author{
Branka Ivančan-Picek, Martina Tudor, Kristian Horvath, Antonio Stanešić, and Stjepan Ivatek-Šahdan \\ Research and Development Department, Meteorological and Hydrological Service, Grič 3, 1000 Zagreb, Croatia \\ Correspondence to: Branka Ivančan-Picek (picek@ cirus.dhz.hr)
}

Received: 15 July 2016 - Published in Nat. Hazards Earth Syst. Sci. Discuss.: 15 August 2016

Revised: 21 November 2016 - Accepted: 23 November 2016 - Published: 14 December 2016

\begin{abstract}
The HYdrological cycle in the Mediterranean EXperiment (HyMeX) is intended to improve the capabilities of predicting high-impact weather events. Within its framework, the aim of the first special observation period (SOP1), 5 September to 6 November 2012, was to study heavy precipitation events and flash floods. Here, we present high-impact weather events over Croatia that occurred during SOP1. Particular attention is given to eight intense observation periods (IOPs), during which high precipitation occurred over the eastern Adriatic and Dinaric Alps. During the entire SOP1, the operational model forecasts generally well represented medium intensity precipitation, but heavy precipitation was frequently underestimated by the ALADIN model at an $8 \mathrm{~km}$ grid spacing and was overestimated at a higher resolution ( $2 \mathrm{~km}$ grid spacing). During IOP2, intensive rainfall occurred over a wider area around the city of Rijeka in the northern Adriatic. The short-range maximum rainfall totals were the largest ever recorded at the Rijeka station since the beginning of measurements in 1958. The rainfall amounts measured in intervals of 20,30 and $40 \mathrm{~min}$ were exceptional, with return periods that exceeded a thousand, a few hundred and one hundred years, respectively. The operational precipitation forecast using the ALADIN model at an $8 \mathrm{~km}$ grid spacing provided guidance regarding the event but underestimated the rainfall intensity. An evaluation of numerical sensitivity experiments suggested that the forecast was slightly enhanced by improving the initial conditions through variational data assimilation. The operational non-hydrostatic run at a $2 \mathrm{~km}$ grid spacing using a configuration with the ALARO physics package further improved the forecast. This article highlights the need for an intensive observation period in the future over the Adriatic region to validate the simulated mechanisms and improve numerical weather predictions via
\end{abstract}

data assimilation and model improvements in descriptions of microphysics and air-sea interactions.

\section{Introduction}

The special observation period 1 (SOP1) of the HYdrological cycle in the Mediterranean Experiment (HyMeX) project was performed from 5 September to 6 November 2012 (Drobinski et al., 2014). The main objective of SOP1 was to improve the understanding and forecasting of the processes that lead to heavy rainfall and floods (Ducrocq et al., 2014). The Mediterranean region is frequently affected by heavy precipitation and flash floods, especially during late summer and autumn. Daily precipitation amounts above $200 \mathrm{~mm}$ have been recorded during this season (e.g. Romero et al., 2000; Buzzi and Foschini, 2000; Jansa et al., 2001; Ducrocq et al., 2008). Within small and densely urbanized areas, intensive and stationary precipitation events can rapidly result in dangerous floods, sometimes leading to disastrous consequences (e.g. Silvestro et al., 2012; Rebora et al., 2013; Ivančan-Picek et al., 2014). This stresses the importance of such events through their impacts on the social and economic circumstances of local communities. Numerical weather prediction (NWP) models have made significant progress through the development of convection permitting systems. However, the ability to predict such high-impact events remains limited because of the contribution of fine-scale processes that are not represented in NWP models, their interactions with the large-scale processes and limitations in data assimilation, especially convective-scale data assimilation. HyMeX aims to improve our understanding of precipitating systems, especially processes responsible for their formation and mainte- 
nance, and to improve the ability of NWPs for forecasting the locations and intensities of heavy precipitation events in the Mediterranean.

The orography and thermal contrasts of the Mediterranean basin, together with approaching upper-level troughs, frequently induce lee cyclogenesis (e.g. Buzzi and Tibaldi, 1978; Horvath et al., 2006) and provide a trigger mechanism for a range of extreme weather phenomena such as local downslope bora windstorms (known as Bura in Croatian) (e.g. Grisogono and Belušić, 2009), strong Scirocco and Tramontana winds (Jurčec et al., 1996; Pandžić and Likso, 2005; Jeromel et al., 2009), orographic precipitation, thunderstorms, supercells and mesoscale convective systems (Ivančan-Picek et al., 2003; Mastrangelo et al., 2011) and waterspouts (Renko et al., 2012). Heavy precipitation preferentially occurs downstream of cyclones aloft (Doswell et al., 1998).

The seasonal distribution of heavy precipitation suggests the relevant role of the high sea surface temperature (SST) of the Mediterranean Sea during the autumn season, when the lower layer of the atmosphere is loaded with water vapour. The large thermal gradient between the atmosphere and the sea favours intense heat and moisture fluxes, which are the energy source for storms (Duffourg and Ducrocq, 2013). Because the sea provides a large source of moisture and heat, the steep slopes of the surrounding mountains near the highly urbanized coastal areas of the Mediterranean are the key factors in determining moisture convergence and the rapid uplift of moist and unstable air responsible for triggering condensation and convective instability processes (e.g. Rotunno and Ferretti, 2001; Davolio et al., 2009). The coastal mountains, however, are not the only sources of lifting. Favourable synoptic upper-level settings, frontal lifting associated with quasi-stationary frontal systems and lower tropospheric mesoscale convective lines may also induce convective instability.

A key component of HyMeX is experimental activity, which is intended to better understand and quantify the water cycle in the Mediterranean, with an emphasis on intense events. Over the entire Mediterranean region, three target areas (TAs) have been proposed for enhanced observational periods (EOPs) to provide detailed and specific observations for studying key processes of the water cycle (http://www.hymex.org). Among them are the Adriatic Sea and Dinaric Alps (the Adriatic TA), which have been proposed for the study of heavy precipitation events and flash floods, and considerable effort from the Croatian meteorological community was put into the campaign (http://www. hymex.org/?page=target_areas).

The Adriatic Sea is a north-west-south-east elongated basin in the central Mediterranean Sea, which is approximately $250 \mathrm{~km}$ wide and $800 \mathrm{~km}$ long and is almost entirely enclosed by mountains, namely the Apennines to the west and south-west, the Alps to the north and the Dinaric Alps to the east and south-east. Those topographic features play a large role in the structure and evolution of the weather systems associated with heavy precipitation (e.g. Vrhovec et al., 2001; Ivančan-Picek et al., 2014). This area is among the rainiest in Europe, with expected annual amounts of precipitation greater than $5.000 \mathrm{~mm}$ in the mountainous hinterland at the southern part of the Adriatic Sea (Magaš, 2002).

Although the Adriatic TA was not part of the extensive experimental activity during SOP1, many events that affected the western Mediterranean also expanded into the Adriatic area. During SOP1, 16 IOPs were dedicated to heavy precipitation events (HPEs) over France, Spain and Italy and many of those events subsequently affected the eastern Adriatic Sea and Croatia.

The aim of the paper is to (1) provide a scientific overview of the HPEs that affected the Adriatic TA during SOP1, (2) provide and examine the operational numerical model skill of the precipitation forecasts in Croatia and (3) provide a detailed description of the extraordinarily rare and heavy IOP2 precipitation event.

The remainder of this paper is organized as follows. Section 2 describes the area of the Dinaric Alps and the Adriatic region and the measured and model data provided by the Croatian Meteorological and Hydrological Service (DHMZ). Section 3 analyses the events during HyMeX SOP1, which produced more than $100 \mathrm{~mm}$ of precipitation during $24 \mathrm{~h}$ on the eastern Adriatic coastline. The performance of the operational precipitation forecasts is assessed through the verification of forecasts, primarily with the Croatian surface observation network. In Sect. 4, additional attention is given to the extraordinarily rare and heavy precipitation IOP2 event.

Finally, we analyse and discuss the potential for improving NWPs through data assimilation using sensitivity experiments. The summary and conclusions are reported in Sect. 5 .

\section{HyMeX SOP1 in Croatia: observations and models}

The Mediterranean is among the most climatically pleasant areas in the world. Nevertheless, the area is prone to highimpact weather phenomena, which affect people's lives and activities and cause extensive material damage. This context was favourable for the active participation of the Croatian scientific community in the HyMeX project. The Croatian research community was active in the preparation of the scientific programme, which included the identification of typical weather patterns over the regions and target areas. During SOP1, the national meteorological service supported the main HyMeX Operational Centre (HOC) in Montpellier (France) by visiting scientists and providing them with meteorological expertise, observations, numerical modelling products and forecast data.

This section summarizes the observational network in Croatia, which was operational during SOP1, and the operational forecasting modelling chain, which produced NWPs during SOP1. 

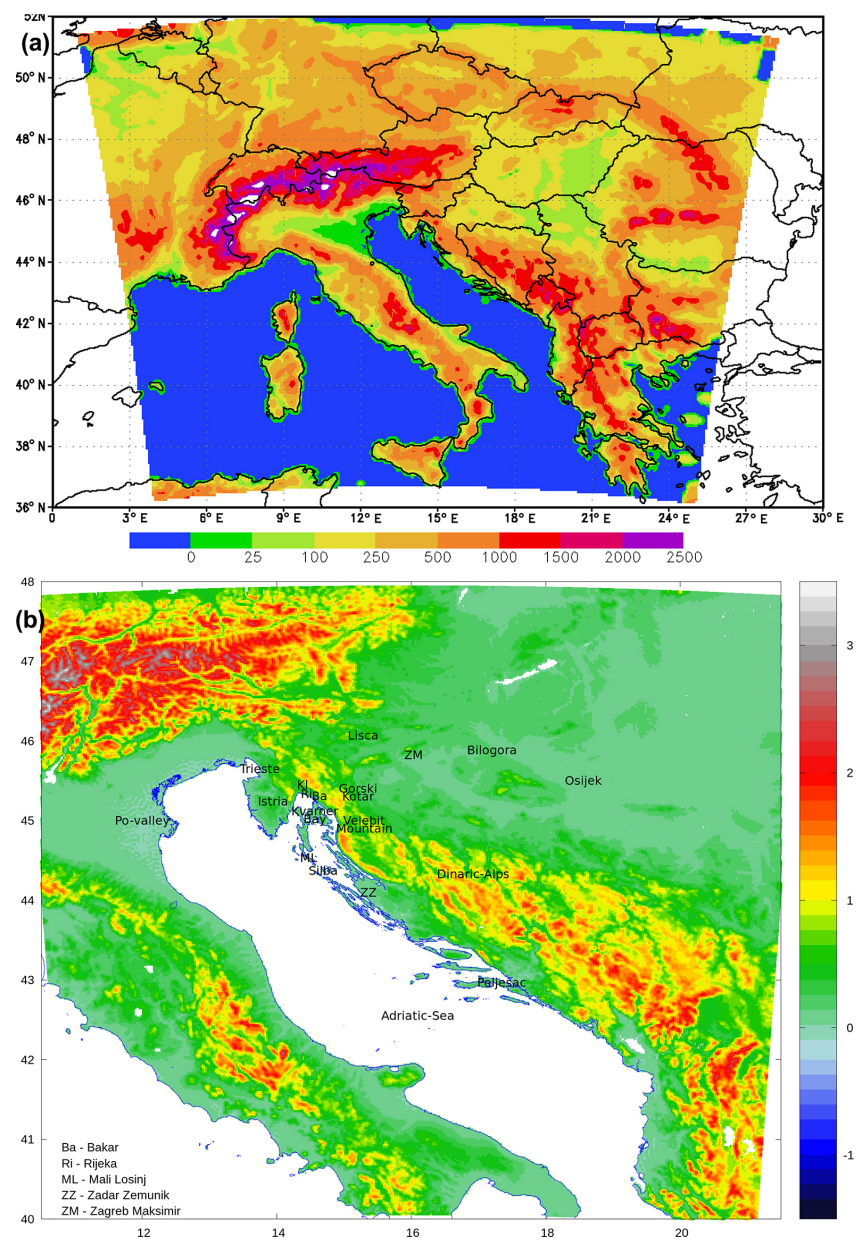

Figure 1. ALADIN model domain and terrain height with $8 \mathrm{~km}$ (a, unit: $\mathrm{m}$ ) and $2 \mathrm{~km}$ (b, unit: $\mathrm{km}$ ) horizontal resolutions.

\subsection{Observations}

The instrumentation deployed over the Adriatic TA during SOP1 belonged mainly to the DHMZ observational network. DHMZ deployed a ground observation operational network that included automatic, climatological and rain gauge stations; two radio-soundings, Zagreb-Maksimir (station $\mathrm{ID}=14240, \mathrm{H}=123 \mathrm{~m}$ a.s.l., $\varphi=45^{\circ} 49^{\prime} \mathrm{N}, \lambda=16^{\circ} 02^{\prime} \mathrm{E}$ ) and Zadar-Zemunik (station ID $=14430, \mathrm{H}=88 \mathrm{~m}$ a.s.l., $\varphi=44^{\circ} 5^{\prime} \mathrm{N}, \lambda=15^{\circ} 21^{\prime} \mathrm{E}$ ), and two radars, Bilogora and Osijek. The locations mentioned in the text are indicated in Fig. $1 b$.

The meteorological measurements and observations from 58 SYNOP stations (31 of which were automatic stations) were made every hour and reported in real time during SOP1. All the automatic stations measured data at $10 \mathrm{~min}$ intervals and reported the measured data in real time. However, not all 63 automatic stations measured all the meteorological parameters. Twenty-one automatic stations only reported wind parameters (average $10 \mathrm{~min}$ speed and direction and wind gust speed measured in the previous $10 \mathrm{~min}$ ). Five additional stations measured wind parameters, temperature and relative humidity. All real-time surface measurements (SYNOP and automatic station data) and available radar figures were stored at the HyMeX data centre.

The dense network of climatological stations (120 stations with an average distance of $20 \mathrm{~km}$ ) was the source of temperature, humidity and wind speed, cloudiness and visibility were estimated from observations only three times per day at 06:00, 13:00 and 20:00 UTC and accumulated rainfall and snow height were measured at 06:00 UTC (more than 500 stations reported accumulated $24 \mathrm{~h}$ rainfall).

In addition to operational radiosoundings in ZadarZemunik at 00:00 and 12:00 UTC, several extra radiosoundings were deployed through the Data Targeting System (DTS) upon request of the HOC. These targeted radiosoundings, among others in the western Mediterranean, were activated during IOP16, which caused heavy precipitation, strong winds and snow in the eastern Adriatic. Requests for additional radiosoundings at 06:00 and 18:00 UTC were carried out under the EUMETNET Observation Programme. Sounding data measured at Zadar-Zemunik, located on the eastern coast of the Adriatic Sea at the southern end of Velebit mountains, provided information on the vertical structure of the troposphere to monitor the upstream flow of the precipitation events in the Adriatic region. The selection of sensitive area predictions (SAPs), that is, predictions for regions where observations are expected to have the largest impact on the forecasts for the verification, used methods developed by ECMWF and Meteo-France (Prates et al., 2009). The verification area selected for SAP calculations was centred over the northern and/or central Adriatic.

To complement the ground-based observations, the data from two radars in Croatia (Bilogora $(\mathrm{H}=270 \mathrm{~m}$ a.s.l., $\left.\varphi=44^{\circ} 53^{\prime} \mathrm{N}, \lambda=17^{\circ} 12^{\prime} \mathrm{E}\right)$ and Osijek $(\mathrm{H}=89 \mathrm{~m}$ a.s.l., $\varphi=45^{\circ} 30^{\prime} \mathrm{N}, \lambda=18^{\circ} 34^{\prime} \mathrm{E}$ )) and one in Slovenia (Lisca; $\mathrm{H}=944 \mathrm{~m}$ a.s.l., $\left.\varphi=46^{\circ} 04^{\prime} \mathrm{N}, \lambda=15^{\circ} 17^{\prime} \mathrm{E}\right)$ were made available operationally in graphical form. Estimates of the instantaneous surface rain rates from the Lisca and Bilogora radars were provided to the HyMeX web server in real time. North-western Croatia, particularly Rijeka and Istria, is covered by operational radars over Croatia, Slovenia and Italy, but the area is on the edge of the ranges and behind a mountain.

Standard Meteosat Second Generation (MSG) Spinning Enhanced Visible and Infrared Imager (SEVIRI) data are available in intervals of $15 \mathrm{~min}$, and Rapid Scan Service (RSS) data are available in 5 min intervals. The abundance of remote sensing data on the HyMeX server encourages detailed analyses of all the cases that produced HPEs over Croatia during SOP1.

Satellite-derived precipitation data from the Tropical Rainfall Measuring Mission were used (TRMM, Huffman et al., 2007). In particular, we used the $3 \mathrm{~h}$ accumulated precipitation data from the $3 \mathrm{~B} 42 \mathrm{RT}$ product to compute the $24 \mathrm{~h}$ accumulated rainfalls for the period from 06:00 to 06:00 UTC the 
next day, and $1 \mathrm{~h}$ precipitation data from the 3B41RT product were compared with the precipitation forecasts developed using operational NWP models.

\subsection{Mesoscale models}

A short description of the model characteristics and the operational set-up during SOP1 is given here.

During SOP1, DHMZ provided the products from the operational forecast (Tudor et al., 2013). At the time, the numerical weather prediction system (NWP) was based on the hydrostatic and non-hydrostatic ALADIN models.

The ALADIN hydrostatic model (Aladin International Team, 1997; Tudor et al., 2013) was run twice per day on a domain with $8 \mathrm{~km}$ resolution (Fig. 1a), starting from 00:00 and 12:00 UTC up to a $72 \mathrm{~h}$ lead time. The operational suite used lateral boundary conditions from the global model ARPEGE run by Meteo-France. The initial fields were obtained using a data assimilation procedure (Stanešić, 2011). The operational ALADIN model is a limited-area model that applies Fourier spectral representation of the model variables using fast Fourier transforms (FFTs) in both directions with a quadratic elliptic truncation (Machenhauer and Haugen, 1987), which ensures an isotropic horizontal resolution and that the non-linear terms of the model equations are computed without aliasing. The forecast at an $8 \mathrm{~km}$ resolution was run on a domain with $240 \times 216$ grid points, which included a band of 11 points along the northern and eastern boundaries, with unphysical terrain created for the biperiodization (Fig. 1a). The dynamical computations were performed using semi-implicit semi-Lagrangian discretisation (Robert, 1982) to solve the hydrostatic dynamics and finite difference method on 37 levels of hybrid pressure type eta coordinates (Simmons and Burridge, 1981) in the vertical. The operational physics package at the time used prognostic TKE, cloud water and an ice, rain and snow and diagnostic scheme for deep convection. The prognostic equations for condensates were solved using the barycentric approach (Catry et al., 2007).

Upon numerous case studies of severe weather events (e.g. Tudor and Ivatek-Šahdan, 2010), an additional operational forecast run was established in July 2011, which used ALADIN with non-hydrostatic dynamics and a complete set of physics parameterisations, including the convection scheme. The high $2 \mathrm{~km}$-resolution forecast using ALADIN model with non-hydrostatic dynamics (Bénard et al., 2010) with the physics package that included the convection scheme was running operationally during the HyMeX SOP1 campaign (Fig. 1b). The convection scheme used in the high-resolution model is modular multiscale microphysics and a transport (3MT) scheme for precipitation and clouds (Gerard and Geleyn, 2005; Gerard, 2007; Gerard et al., 2009).

Both runs used SSTs from the initial file of the global model ARPEGE forecast. Additional details of the model characteristics can be found in Table 1 .

\section{Heavy precipitation events over the Adriatic TA during SOP1}

In the late summer and early autumn of 2012 (from 5 September to 6 November), HyMeX SOP1, which was dedicated to heavy precipitation and flash floods, occurred over the western Mediterranean (Ducrocq et al., 2014). During SOP1, 20 IOPs were declared, and 8 of those events affected the Adriatic TA (Table 2). Most of the events (6 IOPs) were related to HPEs over the northern Adriatic (city of Rijeka).

Figure 2a shows the total precipitation amounts measured by the Croatian rain gauge network accumulated over the entire SOP1. The total precipitation for SOP1 was above the corresponding climatology (Zaninović et al., 2008) for September and October for the Adriatic TA. A similar situation was found over the Apennine Peninsula (Davolio et al., 2015a). The maximum precipitation during SOP1 was recorded in the northern Adriatic (city of Rijeka) and its mountainous hinterland of Gorski Kotar (exceeding $1000 \mathrm{~mm}$ at some locations). There were 15 days with daily rainfall accumulations exceeding $100 \mathrm{~mm}$ at locations in the Adriatic TA (Fig. 2b). There were more IOPs dedicated to HPEs over the Adriatic TA in October than in September 2012, which was also the case in the western Mediterranean (Ducrocq et al., 2014). Several of those events caused local urban flooding (Rijeka, Pula and Zadar), with considerable material damage.

Some of the IOPs were embedded in a synoptic setting conducive to heavy rainfall and characterized by cyclones over western Europe and the Mediterranean (e.g. Dayan et al., 2015). The storm tracks of these cyclones travelling from the North Atlantic to Europe depend on the direction and strength of the westerly winds that are controlled by the relative positions of the permanent Azores high and Icelandic low. Based on Ferretti et al. (2014) and Pantillon et al. (2015), a small positive or negative North Atlantic Oscillation (NAO) index contributed to the evolution of the weather systems associated with heavy precipitation and possibly reduced the long-term predictability over the Mediterranean.

\subsection{Overview of IOPs over the Adriatic TA}

The influence of different meteorological characteristics and physical processes that produced HPEs over the Adriatic TA and Dinaric Alps are briefly analysed and summarized. Previous research on the occurrence of HPEs in the wider Adriatic region (e.g. Doswell et al., 1998; Romero et al., 1998; Vrhovec et al., 2001; Kozarić and Ivančan-Picek, 2006; Horvath et al., 2006; Mastrangelo et al., 2011; Mikuš et al., 2012) highlighted cyclonic activity in the western Mediterranean and Adriatic as a triggering mechanism for a range of extreme weather phenomena, including HPEs. The positions of cyclones that appear in the Adriatic Sea basin strongly influence the climate and weather conditions in the area (Horvath et al., 2008). 
Table 1. Details of the operational model characteristics.

\begin{tabular}{|c|c|c|}
\hline & $8 \mathrm{~km}$ resolution & $2 \mathrm{~km}$ resolution \\
\hline Horizontal discretization & \multicolumn{2}{|c|}{$\begin{array}{l}\text { Spectral, quadratic (Machenhauer and Haugen, 1987) semi-implicit semi-Lagrangian } \\
\text { (Robert, 1982) }\end{array}$} \\
\hline Grid points & $240 \times 216$ & $450 \times 450$ \\
\hline Vertical discretization & \multicolumn{2}{|c|}{37 hybrid pressure type eta coordinates (Simmons and Burridge, 1981) } \\
\hline Equation system & \multicolumn{2}{|c|}{ Prognostic equations for condensates (Catry et al., 2007) } \\
\hline Horizontal diffusion & \multicolumn{2}{|c|}{ SLHD (Váňa et al., 2008) } \\
\hline Time scheme & \multicolumn{2}{|c|}{$\begin{array}{l}\text { SETTLS (Hortal, 2002) with a second-order accurate treatment of the non-linear residual } \\
\text { (Gospodinov et al., 2001) }\end{array}$} \\
\hline Lateral boundary coupling & \multicolumn{2}{|c|}{$\begin{array}{l}\text { Davies (1976) zone } 8 \text { grid-points wide, time dependent (Haugen and Machenhauer, 1993) at the end } \\
\text { of the grid-point computations (Radnóti, 1995) }\end{array}$} \\
\hline LBC data & From ARPEGE, 3 hourly & $\begin{array}{l}6 \mathrm{~h} \text { forecast from } 8 \mathrm{~km} \text { run, hourly (Tudor and } \\
\text { Termonia, 2010) }\end{array}$ \\
\hline Initial conditions & $\begin{array}{l}\text { Stanešić (2011): 3DVar (Courtier et al., 1998; } \\
\text { Lorenc, 1986) and optimal interpolation for surface }\end{array}$ & SSDFI (Termonia, 2008) \\
\hline Microphysics & \multicolumn{2}{|c|}{$\begin{array}{c}\text { prognostic cloud water and ice, rain and snow (Catry et al., 2007) statistical approach for sedimentation } \\
\text { of precipitation (Geleyn et al., 2008) }\end{array}$} \\
\hline Radiation & \multicolumn{2}{|c|}{$\begin{array}{c}\text { (Ritter and Geleyn, 1992) based on Geleyn and Hollingsworth (1979) and enhanced recently } \\
\text { (Geleyn et al., 2005a, b) }\end{array}$} \\
\hline Turbulence & \multicolumn{2}{|c|}{$\begin{array}{l}\text { TKE according to Geleyn et al. (2006), modified from Louis et al. (1982) includes the shallow } \\
\text { convection (Geleyn, 1987) }\end{array}$} \\
\hline Soil scheme & \multicolumn{2}{|c|}{$\begin{array}{l}\text { ISBA (Noilhan and Planton, 1989), also used in the surface data assimilation } \\
\text { (Giard and Bazile, 2000) }\end{array}$} \\
\hline $\begin{array}{l}\text { Diagnostics of } 10 \mathrm{~m} \text { wind } \\
\text { and } 2 \mathrm{~m} \text { temperature }\end{array}$ & \multicolumn{2}{|c|}{$\begin{array}{l}\text { using a parameterised vertical profile (Geleyn, 1988) } \\
\text { dependent on stability }\end{array}$} \\
\hline Convection & diagnostic convection scheme (Geleyn et al., 1995) & $\begin{array}{l}\text { prognostic convection scheme (Gerard and Geleyn, } \\
\text { 2005; Gerard, 2007) combines resolved and convective } \\
\text { contributions (Gerard et al., 2009) }\end{array}$ \\
\hline
\end{tabular}

Table 2. HPEs over the Adriatic TA during SOP1. The column titled Rainfall lists the maximum $24 \mathrm{~h}$ accumulated precipitation (from 06:00 to 06:00 UTC). Weather regime gives associated large scale weather.

\begin{tabular}{lllrl}
\hline Date & IOP & Location & Rainfall (mm) & Weather regime \\
\hline 12-13 Sep & 2 & Rijeka & 220.2 & NAO+, cold front, SW advection \\
13-14 Sep & 4 & Pelješac & 101.4 & NAO+, cyclone, bora and sirocco \\
1-2 Oct & 9 & Rijeka & 127.4 & NAO+, cold front, SW advection \\
11-13 Oct & 12a & Silba, Šolta, Prevlaka & 121.0 & blocking, cold front, SW advection \\
14-16 Oct & 13 & Hvar, Mljet, Rijeka, Karlobag, Imotski & $118.6,145.4$ & blocking, cold front, SW advection \\
26-28 Oct & 16 & Rijeka, Rijeka inland & $180.1,173.5$ & NAO-, blocking, cyclone, sirocco, aqua alta \\
31 Oct-2 Nov & 18 & Istria, Rijeka & 171.4 & NAO-, cyclone, sirocco, aqua alta \\
4-5 Nov & 19 & Rijeka inland & 177.0 & NAO-, cyclone, SW advection \\
\hline
\end{tabular}

During SOP1, several upper-level troughs entered the western Mediterranean and induced cyclogenesis over the Gulf of Genoa, Tyrrhenian Sea and Adriatic Sea. Figure 3 shows the mean sea level pressures and low-level horizontal winds for IOP4, IOP9, IOP13, IOP16, IOP18 and IOP19. A1- though most of the events were related to cyclone activity in the region, some events were not characterized by a cyclone moving over the area. In the following text, we summarize the analyses of selected characteristic IOPs that affected the Adriatic area. Large-scale conditions similar to those found 

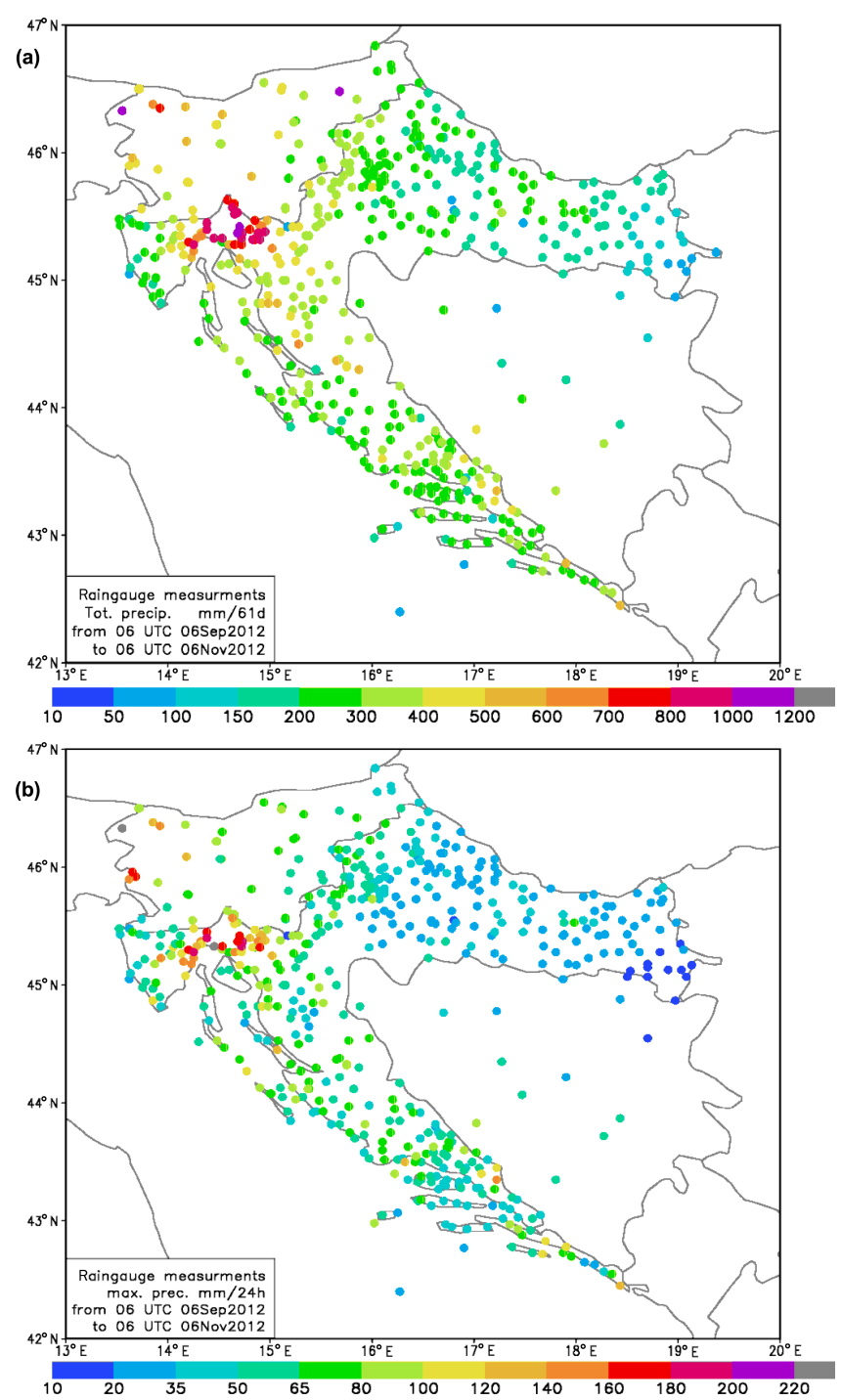

Figure 2. (a) Total precipitation measured by the Croatian rain gauge network, cumulated over the entire SOP1 period. (b) Maximum $24 \mathrm{~h}$ rainfall totals at each rain gauge station during SOP1.

in the IOPs helped generate mesoscale and local processes, leading to quite different precipitation patterns.

\subsubsection{IOP4}

This event was caused by a mesoscale cyclone associated with a potential vorticity (PV) anomaly over the Adriatic Sea and was enhanced by the low-level convergence of the bora flow over the northern Adriatic Sea and warm southerly wind in the southern Adriatic (Fig. 3a). The mesoscale cyclone moved slowly south-eastward, inducing instability over central Adriatic Sea, with intense convective phenomena on both sides of the basin.

Several rain gauge stations reached maxima of over 150 $200 \mathrm{~mm} / 24 \mathrm{~h}$ along the eastern Italian coast (Maiello et al.,
2014), and more than $100 \mathrm{~mm} / 24 \mathrm{~h}$ was recorded over the south-east coast of the Adriatic, with a maximum over the Pelješac peninsula (Fig. 1b). As inferred from the satellite data, there were also other local precipitation maxima over the sea (Fig. 4b). Previous studies (e.g. Buzzi and Foschini, 2000; Ivančan-Picek et al., 2014; Davolio et al., 2016) have shown that the largest component of the mountain-rangescale precipitation appears to be due to the orographic lifting of moist and impinging low-level flows. Consequently, the vertical uplifts forced by the Dinaric Alps area were favourable for the initiation and maintenance of convection. However, the coastal mountains close to the Adriatic Sea were not the only sources of lift. Low-level circulation over the sea frequently generates low-level convergence responsible for convective initiation (Jansa et al., 2001; Davolio et al., 2009). The mesoscale cyclone over the Adriatic and frontal system moved slowly south-eastward and induced instability over the central Adriatic Sea due to the strong low-level convergence between the southerly jugo (sirocco) and northeasterly bora winds. This caused more than $100 \mathrm{~mm} / 24 \mathrm{~h}$ to be recorded over the south-eastern Adriatic coast and the open sea (Fig. 4b).

In IOP4, heat loss caused by a strong bora wind was very intensive. The bora was severe on the northern Adriatic and exceeded $24 \mathrm{~m} \mathrm{~s}^{-1}$. Strong bora winds bring cold and dry continental air over the warm Adriatic basin, which generate intense air-sea heat exchanges and rapid sea surface cooling (e.g. Grisogono and Belušić, 2009). The proper representation of sea surface temperatures (SSTs) in the numerical models, especially in small and shallow basins, such as the Adriatic Sea, is necessary for improving short-range precipitation forecasts (e.g. Davolio et al., 2015b; Stocchi and Davolio, 2016; Ricchi et al., 2016). The response of heavy precipitation to an SST change is complex and mainly involves modification to the boundary layer characteristics, flow dynamics and its interaction with the orography. In the numerical modelling, the SST representation is generally unrealistic and usually keeps the SST fixed at its initial value. Furthermore, especially in a narrow and inhomogeneous basin such as the Adriatic, small-scale SST variations cannot be properly represented in coarse large-scale analyses, especially near the coasts. Figure 4a shows SST measured at the Bakar station close to the city of Rijeka for the entire SOP period. During IOP4 (13-14 September 2012), the SST rapidly decreased by $10^{\circ} \mathrm{C}$ at the Bakar station in comparison to representation in the operational model, which used LBC from the global ARPEGE model. Therefore, the SST near the coast was colder than that in the ALADIN model forecast, which affected the ability of the forecast model to properly forecast the meteorological fields there. In addition to operational SST, a control simulation was driven by the SST field provided by the OSTIA analyses (Donlon et al., 2012), which better corresponded to in situ observations during this event. The daily accumulated precipitation for the operational $2 \mathrm{~km}$ model run and the control simulation with modified colder 

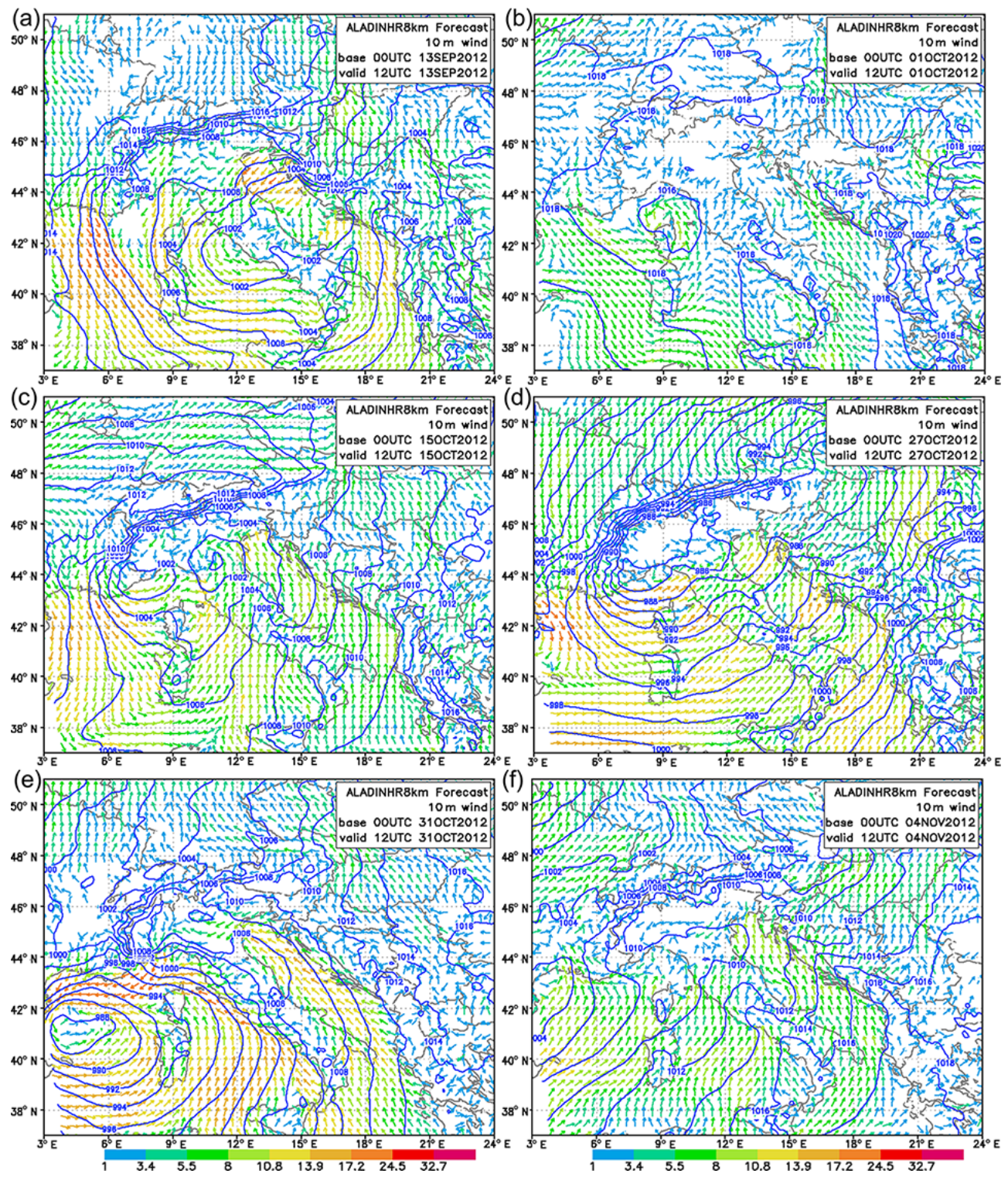

Figure 3. Horizontal wind at $10 \mathrm{~m}$ (arrows coloured according to wind speed) and mean sea level pressure (blue isolines) forecasts by the ALADIN 8 km-resolution run for 12:00 UTC for (a) IOP4 (13 September), (b) IOP9 (1 October), (c) IOP13 (15 October), (d) IOP16 (27 October), (e) IOP18 (31 October), (f) IOP19 (4 November).

SST from OSTIA are presented in Fig. $4 \mathrm{~d}$ and e. In this case, the control simulation using the OSTIA analysis was more realistic (see Fig. 4b) and generally drier than the operational model with a warmer SST. The colder SST caused a decrease in precipitation over the mountainous Adriatic coast.

IOP4 shows the need for further improvements in the role of SST and surface (latent and sensible) heat fluxes over the Adriatic Sea, which attain large values during strong bora events. However, a more detailed analysis of the impact of SST on precipitation is ongoing.

\subsubsection{IOP13}

Several events were characterized by frontal lifting associated with quasi-stationary frontal systems that helped release convective instability (IOP9, IOP12 and IOP13). Here, we will focus on the IOP13 event, which affected the entire eastern Adriatic coast and all three Italian TAs (Ferretti et al., 2014).

Smooth troughs that produced a south-westerly flow over the Adriatic TA were observed entering the western Mediterranean Sea. A cold front moved eastward, supporting the advection of moist air at low levels towards the coastline. This warm and moist air ahead of the front organized in- 

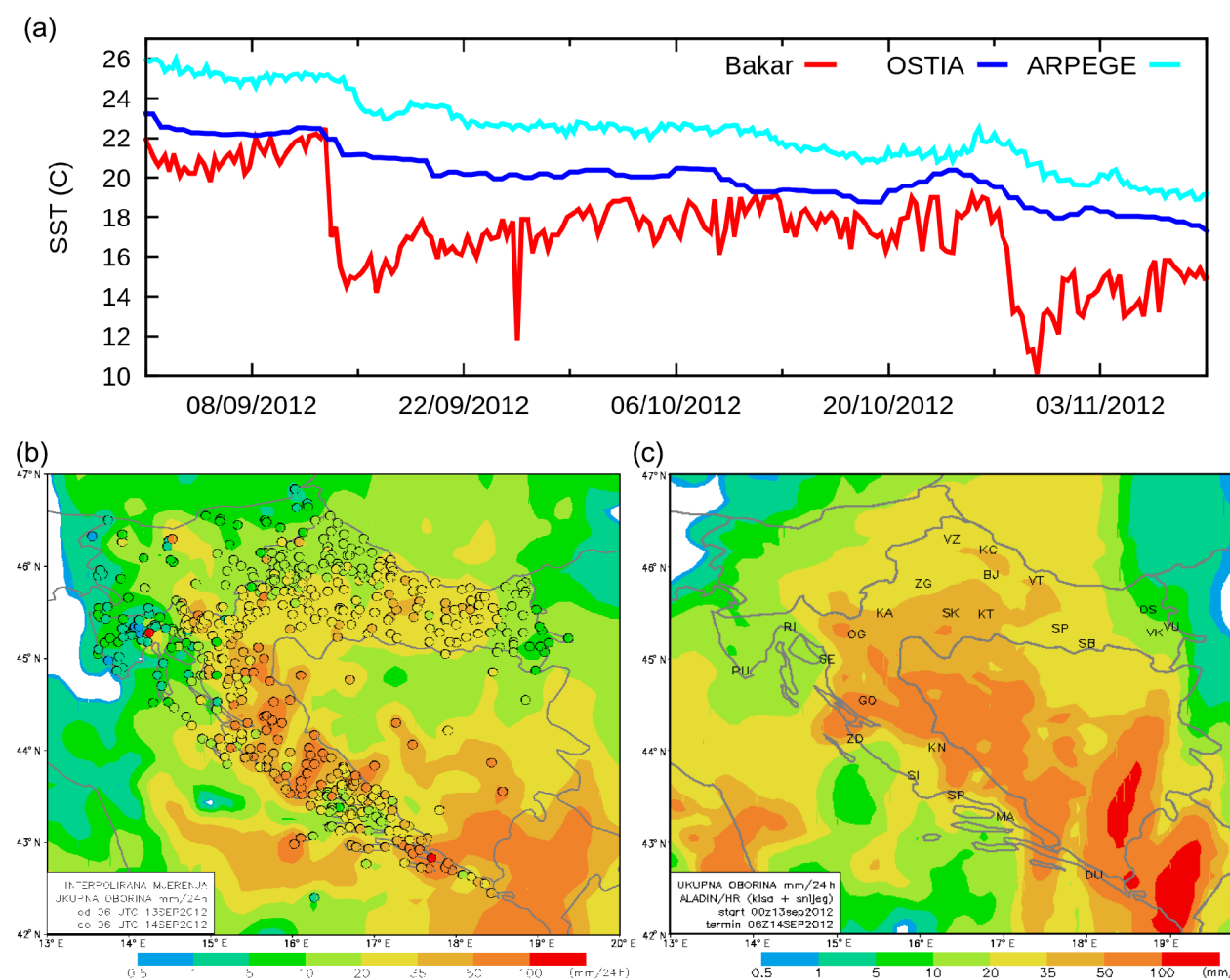

(c)

(d)
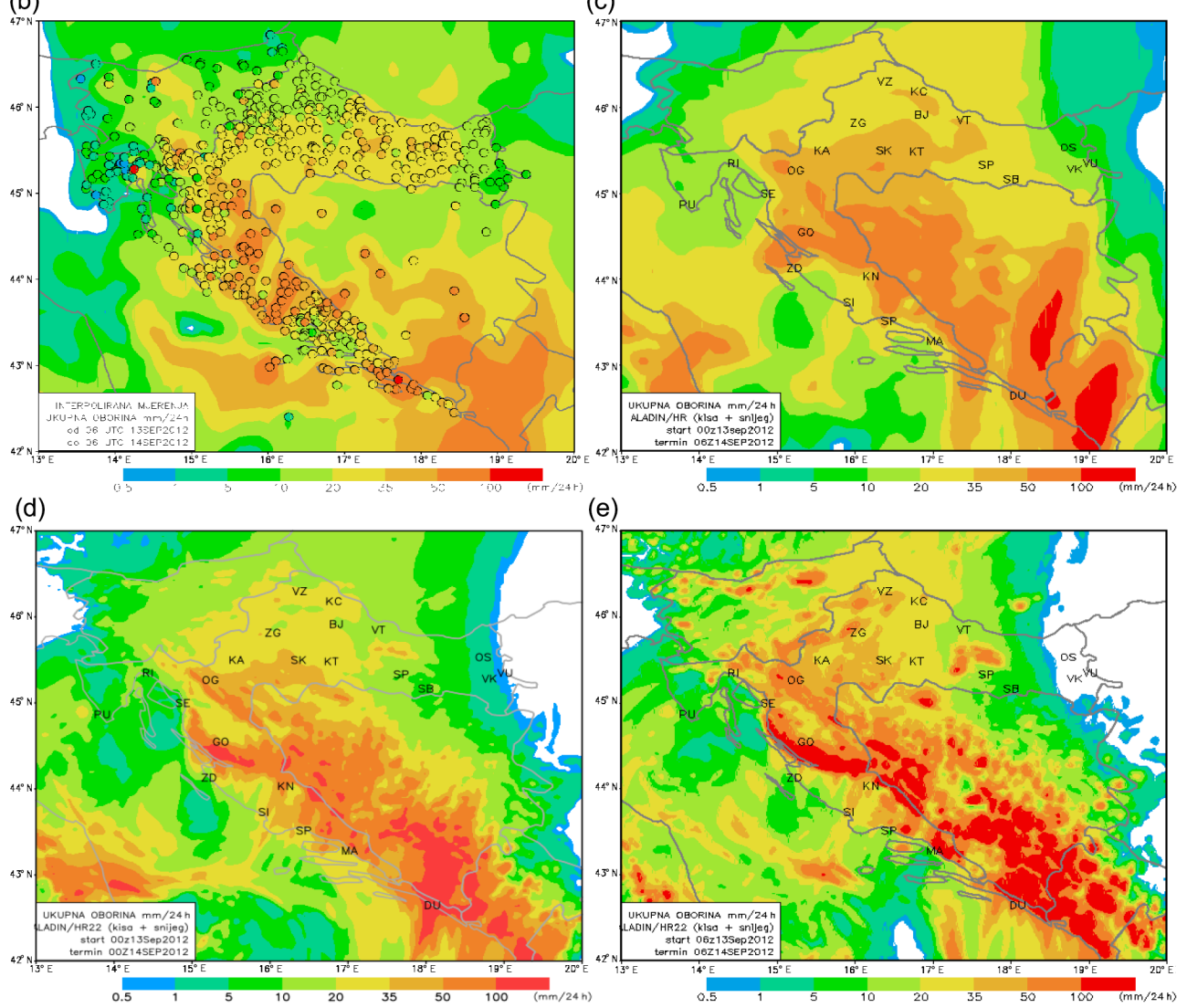

(e)

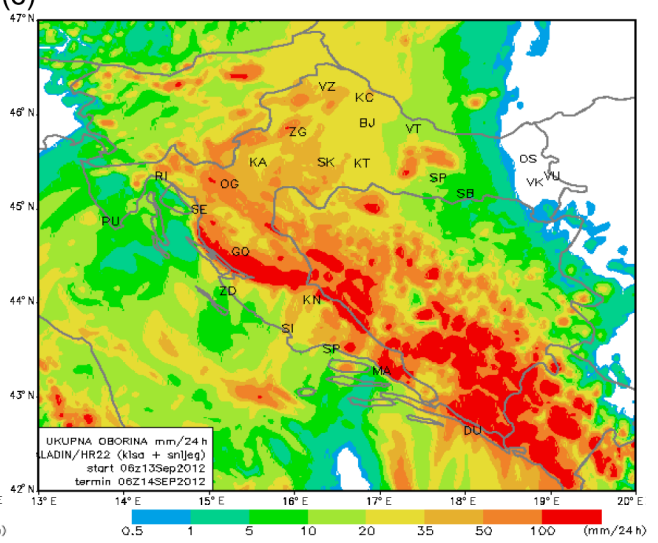

Figure 4. (a) Sea surface temperature measured in situ (red) at the Bakar station, which was close to the city of Rijeka, and the nearest sea point data used in the ALADIN $8 \mathrm{~km}$-resolution model from the global ARPAGE model (light blue) and OSTIA (blue) for SOP1 from 5 September to 8 November 2012. For IOP4 (14 September) (b) shows accumulated $24 \mathrm{~h}$ rainfall measured on rain gauges (circles) and interpolated using data from rain gauges and 3B42RT3 hourly product for periods starting at 06:00 UTC; (c) shows accumulated 24 h precipitation forecasts from the ALADIN $8 \mathrm{~km}$-resolution run; (d) shows accumulated $24 \mathrm{~h}$ precipitation forecasts from the ALADIN $2 \mathrm{~km}$ resolution run with SST from OSTIA and (e) shows accumulated $24 \mathrm{~h}$ precipitation forecasts from the ALADIN $2 \mathrm{~km}$-resolution run with SST from the ARPAGE global model.

tensive convective activity that formed a rain band stretching from Tunisia over southern Italy to south-eastern Croatia. During the evening of 15 October, a Genoa cyclone developed and, with an associated frontal system, moved rapidly over Italy. The advection of the moist air from over the sea caused deep convection and another cut-off low that developed over northern Italy and moved eastward. This weather regime (Fig. 3c) provided a favourable environment for HPEs, with thunderstorms over the northern Adriatic Sea, where $127.4 \mathrm{~mm} / 24 \mathrm{~h}$ was recorded in the city of Rijeka in the northern Adriatic. Figure 5a shows the daily accumulated rainfall on 16 October recorded by the Slovenian and Croatian rain gauge networks and the interpolation with the 3B42RT product. The low-level wind field was dominated by a low-level jet stream that carried the warm and humid Mediterranean air to the Adriatic Sea (Fig. 3c). This situa- 
tion was favourable for the strong S-SE sirocco wind, which is known as the jugo in Croatian (e.g. Jurčec et al., 1996). The advection of warm and moist Mediterranean air caused intensive precipitation, which exceeded $100 \mathrm{~mm} / 24 \mathrm{~h}$ over the northern Adriatic and open sea and several of the outermost islands (Mali Lošinj, Silba, Hvar and Mljet).

In less than $24 \mathrm{~h}$, intense precipitation exceeding $120 \mathrm{~mm}$ affected the northern Adriatic area. The precipitation timing and the location of the maxima were reproduced quite well in the model forecasts (Fig. $5 b$ and c). The operational forecast at a $2 \mathrm{~km}$ grid resolution better simulated the extreme amounts in the Rijeka area than the operational forecast at an $8 \mathrm{~km}$ grid resolution. However, both models overestimated the rainfall over the southern Adriatic mountainous area.

\subsubsection{IOP16 and IOP18}

These events represent excellent cases for the science issues identified in the HyMeX programme for the western Mediterranean (convection initiation, cloud-precipitation processes and air-sea coupled processes). These situations produce favourable conditions for HPEs on the southern side of the Alpine ridge, including the northern Adriatic region.

During these events, the Adriatic TA was strongly affected by the Genoa cyclone (IOP16) and the intensive western Mediterranean cyclone (IOP18) inducing low-level southeasterly and south-westerly flow over the Adriatic area.

Figure $3 \mathrm{~d}$ and e shows the sea level pressure and low-level wind vectors at 12:00 UTC on 27 and 31 October. This situation was favourable for the strong S-SE jugo wind (IOP18), which carried the warm and humid Mediterranean air to the Adriatic Sea. The cyclone during IOP16 caused the lowest pressure recorded over the Adriatic TA during the entirety of SOP1. The advection of the warm air combined with intensive advection of cyclonic vorticity contributed to the strong upward motion in the area of the northern Adriatic and the adjacent mountains, resulting in $180 \mathrm{~mm}$ of precipitation over the city of Rijeka and the mountainous hinterland (Fig. 6a). Very intensive convective activity during IOP18, with heavy showers and thunderstorms, again produced more than $170 \mathrm{~mm} / 24 \mathrm{~h}$ in Rijeka (Fig. 7a).

During IOP16, targeted radio-soundings intended for data assimilation, case analysis and verification were deployed over the central Mediterranean area and Adriatic area. The time evolution of the vertical structure of troposphere on the eastern Adriatic coast was inferred through a deployed DTS and standard radiosoundings at Zadar-Zemunik during 2628 October (Fig. 8). A gradual moistening of the lower troposphere occurred on 26 October at the same time as a southeasterly near-surface jugo wind in the Adriatic basin and south-westerly flow aloft. The air column below $500 \mathrm{hPa}$ was nearly saturated and rather moist above. On 26 October, this moistening was still not associated with significant values of convective available potential energy (CAPE). The next day, however, CAPE increased to over $1200 \mathrm{~J} \mathrm{~kg}^{-1}$ on 12:00 UTC
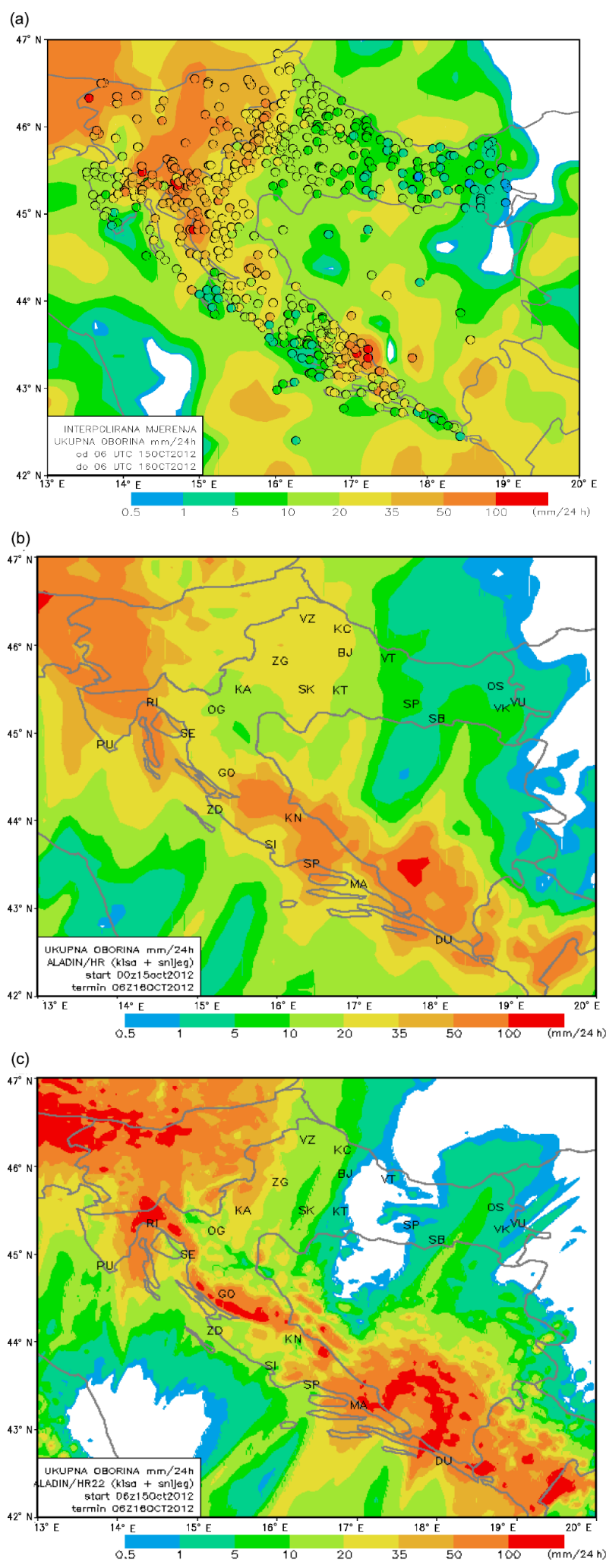

Figure 5. IOP13 (16 October): (a) accumulated $24 \mathrm{~h}$ rainfall measured on rain gauges (circles) and interpolated using data from rain gauges and the 3B42RT3 hourly product for periods starting at 06:00 UTC; accumulated $24 \mathrm{~h}$ precipitation forecasts (b) for the ALADIN $8 \mathrm{~km}$-resolution run (starting from 00:00 UTC on the same day and (c) for the ALADIN 2 km-resolution run. 

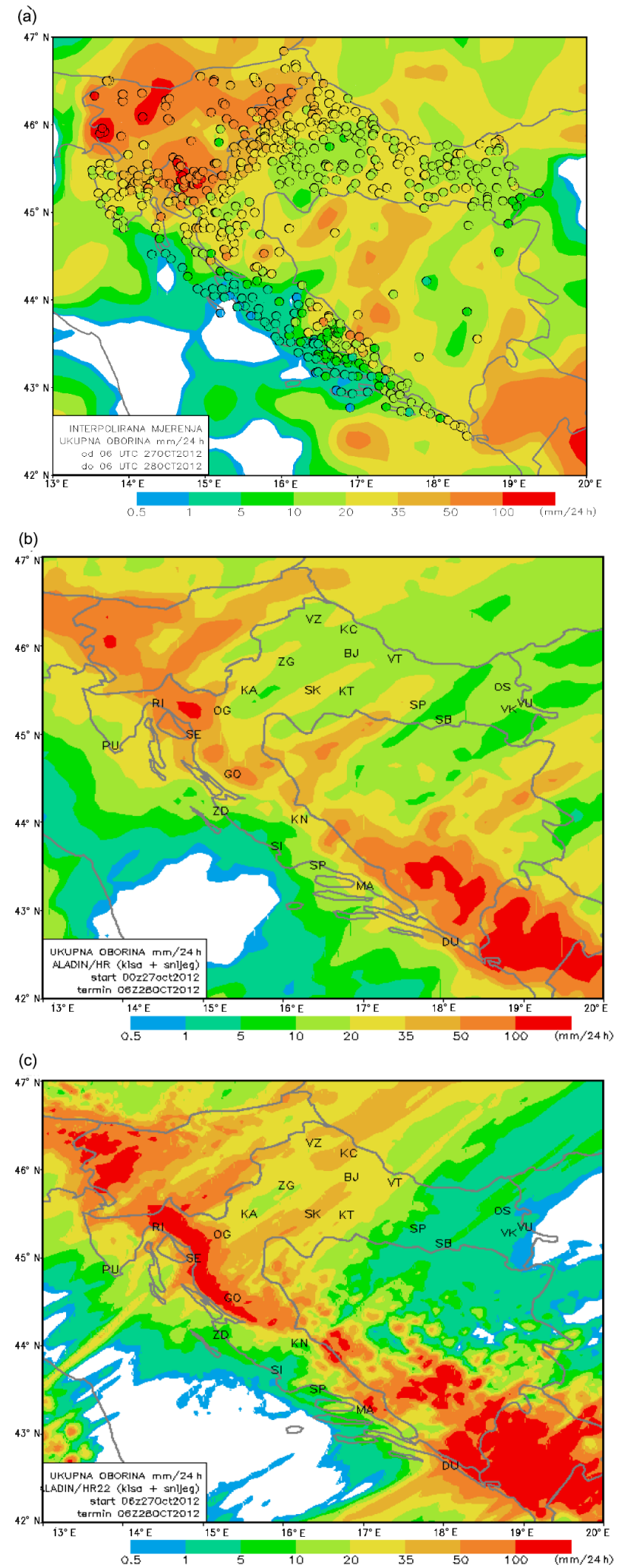

Figure 6. Same as Fig. 5 but for IOP16 (28 October).
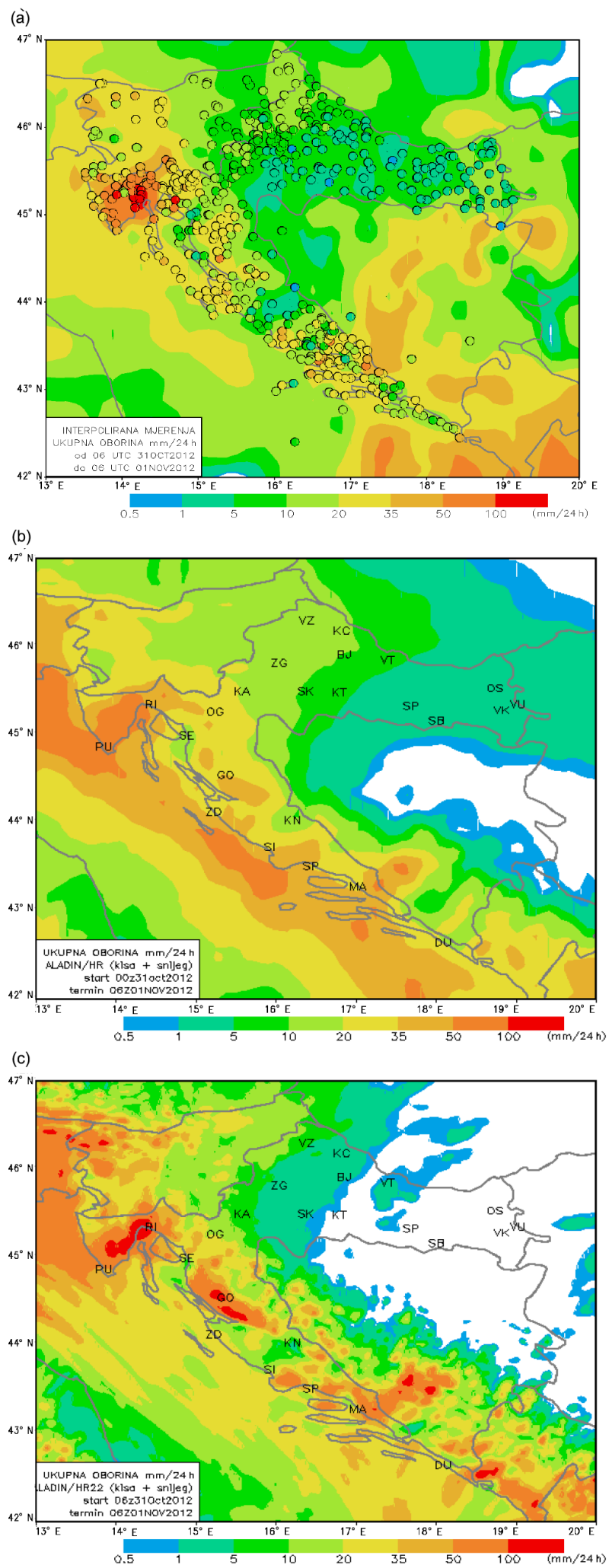

Figure 7. Same as Fig. 5 but for IOP18 (1 November). 

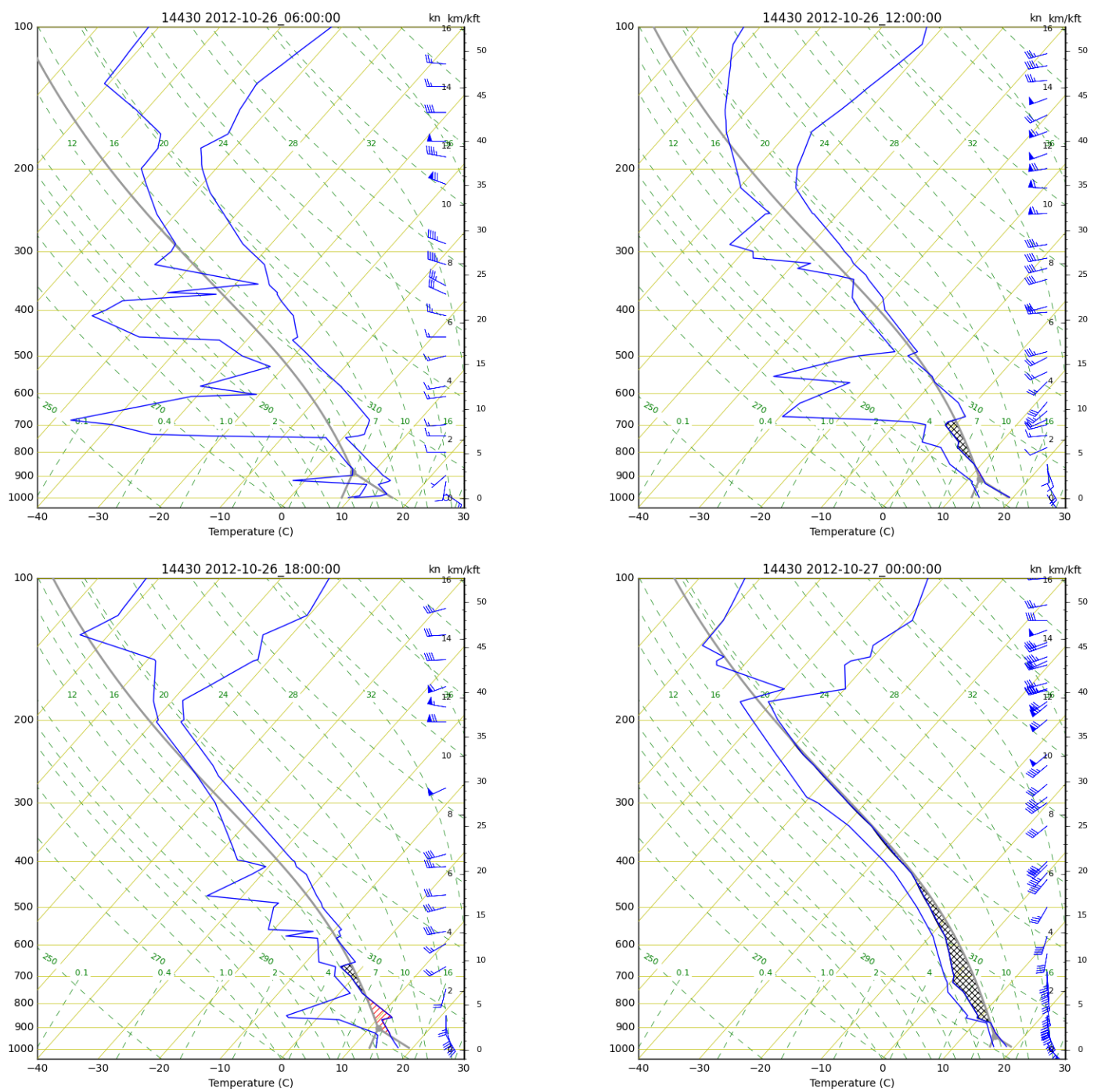

Figure 8. Radiosounding data for Zadar 26 October 2012 at 06:00 and 12:00 UTC (first row), 26 October 2012 at 18:00 UTC and 27 October 2012 at 00:00 UTC (second row).

and over $1000 \mathrm{~J} \mathrm{~kg}^{-1}$ on 18:00 UTC 27 October. The winds strengthened throughout the troposphere, and the highest intensity was observed in the layer between 300 and $200 \mathrm{hPa}$. A strong south-westerly shear of approximately $20 \mathrm{~m} \mathrm{~s}^{-1}$ in the first $2 \mathrm{~km}$ of the troposphere was also present over this area.

Both IOPs (IOP16 and IOP18) were fairly well forecast (Figs. 6 and 7). The precipitation timing and the location of the maxima were reproduced quite well in the model forecasts. In less than $24 \mathrm{~h}$, intense precipitation exceeding $170 \mathrm{~mm}$ affected the northern Adriatic area. The operational forecast of the $2 \mathrm{~km}$-model-resolution run overestimated rainfall above mountains, but it was consequently closer to the extreme amounts in the Rijeka area.

The sirocco wind is the cause of a piling up of Adriatic water near the northernmost coasts that occasionally floods the city of Venice (Orlić et al., 1994). This was also the case during the IOP16 and IOP18. The Venetian Lagoon was hit by acqua alta (high water), the warning level was exceeded twice, with more than $120 \mathrm{~mm}$ on 27 and 28 October (Ferretti et al., 2014) and more than $140 \mathrm{~mm}$ was measured on 1 November 2012.

\subsubsection{IOP19}

During the entirety of IOP19 (3-5 November 2012), the south-westerly advection of warm and humid air produced convection over the northern Adriatic and orographic precipitation along the Kvarner Bay. A south-westerly flow over the entire region of the western Mediterranean was produced by a baroclinic wave that formed over north-western Europe to northern Africa due to weakened westerlies and low NAO. Strong south-westerly flow in the lower troposphere ahead of the cold front supported the advection of moist and warm air. 
Additional details on the synoptic situation are described in Ferretti et al. (2014) and Davolio et al. (2016). More rainfall was recorded on rain gauges on the north-eastern Adriatic coast. During this event, $177.0 \mathrm{~mm} / 24 \mathrm{~h}$ was recorded in Klana, the hinterland of the city of Rijeka (Fig. 9), and the precipitation was mainly orographic-forced with a strong south-east jugo (sirocco) wind (Fig. 3f). This represents typical events in this area, which are generally well forecasted by operational models, because they can describe the main orographic forcing properly. Both versions of the ALADIN operational models ( 8 and $2 \mathrm{~km}$ resolution) produced maximum precipitation over the mountainous hinterland of the city of Rijeka (Fig. 9b and c). The amount of precipitation was slightly underestimated. In addition, the $2 \mathrm{~km}$ nonhydrostatic version of the model produced the second maximum over the Velebit mountain, which was not observed. This result implies that ALADIN $2 \mathrm{~km}$ overestimated the orographic forcing associated with the higher ridges of the Dinaric Alps.

\subsection{Verification of the precipitation forecasts during SOP1}

The performances of the operational precipitation forecasts with the ALADIN model at $8 \mathrm{~km}$ and ALADIN model at $2 \mathrm{~km}$ grid spacing during SOP1 were assessed by comparing the forecasts with the measurements from the Croatian surface observation network. The model results were compared with $24 \mathrm{~h}$ accumulated precipitation measured by the rain gauges. Before the calculation of the verification score results for ALADIN $2 \mathrm{~km}$, the model was upscaled to an ALADIN $8 \mathrm{~km}$ grid to avoid double penalty errors and make a more direct comparison. The precipitation amount from the ALADIN ( $8 \mathrm{~km}$ and upscaled $2 \mathrm{~km}$ ) model was obtained from the nearest model point with respect to the observation location. Contingency tables (Tables 3 and 4) were evaluated with three categories defined according to the amount of $24 \mathrm{~h}$ accumulated precipitation and classified as dry, medium and strong. An event was defined as dry if the $24 \mathrm{~h}$ accumulated precipitation on the rain gauge station was less than or equal to $0.2 \mathrm{~mm} / 24 \mathrm{~h}$. The border between the medium and strong categories was defined as the 95th percentile of the measured $24 \mathrm{~h}$ accumulated precipitation $(50.42 \mathrm{~mm} / 24 \mathrm{~h})$ during the SOP1 period, but with the dry events excluded.

Figure 10 presents the $24 \mathrm{~h}$ accumulated precipitation histograms from both the models and rain gauges during the entire SOP1 period and during the specific days corresponding to the 8 IOPs indicated in Table 1 . The measurements show that a large percentage of the events were dry $(64.7 \%)$ during the entire SOP1 period. The value corresponding to the 95th percentile $(50.4 \mathrm{~mm})$ is indicated on the graph, and it appears to be a reasonable threshold for the heavy precipitation events that we want to verify. As expected, the histogram for only the IOP days (8 IOP cases) shows that the number of dry events was reduced $(18.1 \%)$, and the relative frequency
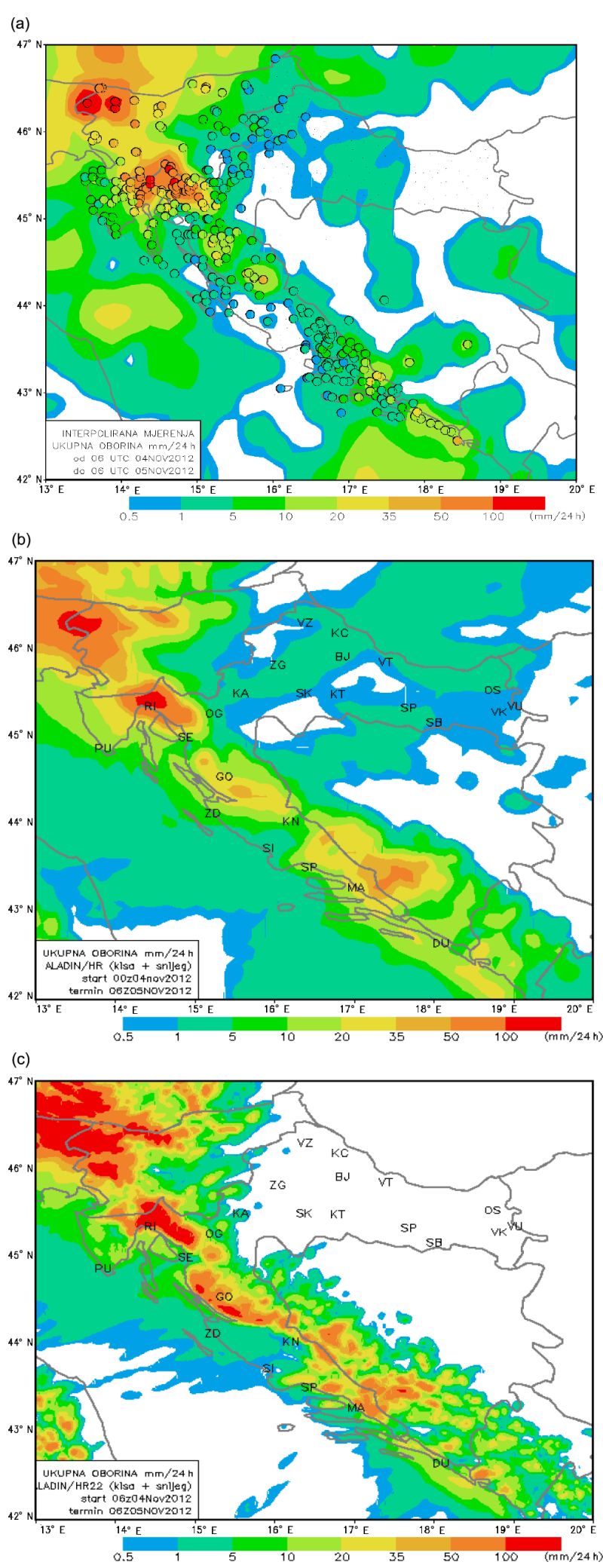

Figure 9. Same as Fig. 5 but for IOP19 (4 November). 
Table 3. Verification measures calculated for $24 \mathrm{~h}$ accumulated precipitation and for ALADIN $8 \mathrm{~km}$ model (second column) for three categories (first column), for the whole SOP1 period (5 September to 6 November 2012), only IOP days (IOPavg), and for selected IOPs corresponding to time periods indicated in Table 1 and for IOP2 without data assimilation experiment (IOP2 no DA). Verification measures include base rate (BR), frequency bias (FBIAS), critical success index (CSI) and polychoric correlation coefficient (PCC). Due to zeros in contingency table some PCC scores could not be calculated (IOP4 and IOP16 for ALADIN $8 \mathrm{~km}$ model).

\begin{tabular}{|c|c|c|c|c|c|c|c|c|c|c|c|c|}
\hline \multirow[t]{2}{*}{ Cat. } & \multirow[t]{2}{*}{ Measure } & \multirow[b]{2}{*}{ SOP1 } & \multicolumn{10}{|c|}{ Period } \\
\hline & & & IOPavg & IOP2 & $\begin{array}{r}\text { IOP2 } \\
\text { no DA }\end{array}$ & IOP4 & IOP9 & IOP12a & IOP13 & IOP16 & IOP18 & IOP19 \\
\hline \multirow[t]{3}{*}{ Dry } & $\mathrm{BR}[\%]$ & 64.7 & 18.1 & 15.5 & 15.5 & 2.7 & 12.7 & 27 & 30.9 & 2.9 & 10.6 & 44.7 \\
\hline & FBIAS & 0.78 & 0.29 & 0.5 & 0.41 & 0 & 0.15 & 0.47 & 0.45 & 0 & 0.01 & 0 \\
\hline & CSI & 0.73 & 0.23 & 0.16 & 0.16 & 0 & 0.08 & 0.39 & 0.41 & 0 & 0.01 & 0 \\
\hline \multirow{3}{*}{ Medium } & $\mathrm{BR}[\%]$ & 33.6 & 74.5 & 60.1 & 60.1 & 86.9 & 86.4 & 69.8 & 62.9 & 87.9 & 85.1 & 49.6 \\
\hline & FBIAS & 1.45 & 1.2 & 1.36 & 1.39 & 1.03 & 1.1 & 1.24 & 1.26 & 1.09 & 1.14 & 1.91 \\
\hline & CSI & 0.62 & 0.76 & 0.59 & 0.59 & 0.84 & 0.84 & 0.76 & 0.65 & 0.88 & 0.86 & 0.5 \\
\hline \multirow[t]{4}{*}{ Strong } & $\mathrm{BR}[\%]$ & 1.8 & 7.3 & 24.3 & 24.3 & 10.4 & 0.8 & 3.3 & 6.3 & 9.3 & 4.3 & 5.7 \\
\hline & FBIAS & 0.63 & 0.73 & 0.42 & 0.42 & 0.98 & 3.75 & 0.19 & 1.13 & 0.42 & 0.69 & 0.89 \\
\hline & CSI & 0.2 & 0.23 & 0.28 & 0.23 & 0.22 & 0 & 0 & 0.08 & 0.19 & 0.39 & 0.39 \\
\hline & PCC & 0.8987 & 0.6847 & 0.5926 & 0.5488 & - & 0.3265 & 0.7489 & 0.7056 & - & 0.8824 & 0.7182 \\
\hline
\end{tabular}

Table 4. Same as Table 2 but verification measures are calculated for ALADIN $2 \mathrm{~km}$ model.

\begin{tabular}{llrrrrrrrrrr}
\hline Cat. & Measure & \multicolumn{9}{c}{ Period } & \multicolumn{1}{c}{} \\
\cline { 3 - 11 } & & SOP1 & IOPavg & IOP2 & IOP4 & IOP9 & IOP12a & IOP13 & IOP16 & IOP18 & IOP19 \\
\hline \multirow{2}{*}{ Dry } & BR [\%] & 64.7 & 18.1 & 15.5 & 2.7 & 12.7 & 27.0 & 30.9 & 2.9 & 10.6 & 44.7 \\
& FBIAS & 0.92 & 0.81 & 0.83 & 1.69 & 1.29 & 0.76 & 0.74 & 0.79 & 0.64 & 0.84 \\
& CSI & 0.78 & 0.39 & 0.18 & 0.00 & 0.15 & 0.39 & 0.59 & 0.19 & 0.04 & 0.68 \\
\hline \multirow{2}{*}{ Medium } & BR [\%] & 33.6 & 74.5 & 60.1 & 86.9 & 86.4 & 69.8 & 62.9 & 87.9 & 85.1 & 49.6 \\
& FBIAS & 1.12 & 1.00 & 1.11 & 0.85 & 0.86 & 1.12 & 1.07 & 0.98 & 1.01 & 1.09 \\
& CSI & 0.59 & 0.71 & 0.50 & 0.70 & 0.69 & 0.73 & 0.69 & 0.83 & 0.76 & 0.64 \\
\hline \multirow{2}{*}{ Strong } & BR [\%] & 1.8 & 7.3 & 24.3 & 10.4 & 0.8 & 3.3 & 6.3 & 9.3 & 4.3 & 5.7 \\
& FBIAS & 1.65 & 1.49 & 0.84 & 2.08 & 10.75 & 0.38 & 1.64 & 1.22 & 1.76 & 1.46 \\
& CSI & 0.17 & 0.20 & 0.32 & 0.21 & 0.00 & 0.05 & 0.21 & 0.18 & 0.18 & 0.19 \\
& PCC & 0.8407 & 0.624 & 0.5302 & 0.3987 & 0.2083 & 0.4933 & 0.7896 & 0.3233 & 0.326 & 0.7854 \\
\hline
\end{tabular}

of events shifted towards events with higher amounts of precipitation.

Although the ALADIN $8 \mathrm{~km}$ model distribution was in rather good agreement with the rain gauge measurements during the entire SOP1 period, with the exception of the most intensive rain, the model distribution for the IOP days only shows that the model tended to underestimate the frequencies of the weak and strong precipitation events, whereas it overestimated the frequency of moderate precipitation events. For ALADIN $2 \mathrm{~km}$ SOP1 and IOP days only, the histograms show similar results; the model tended to underestimate moderate precipitation, whereas at the same time it tended to overestimate strong precipitation. A comparison of the two models shows that the ALADIN $2 \mathrm{~km}$ model better agreed with the measurements, especially for very weak and strong precipitation.
The verification measures (Wilks, 2006) calculated from the comparison of the $24 \mathrm{~h}$ accumulated precipitation from the rain gauges and model for the three categories and different periods are summarized in Tables 3 and 4. The indices used here are defined in the Appendix. Because most of the measures are base rate (BR) sensitive and can be safely used only to compare two models for the same event, the polychoric correlation coefficient (PCC; Juras and Pasarić, 2006) was calculated as an additional measure because PCC does not depend on BR or frequency bias (FBIAS). For both ALADIN models, PCC showed rather high levels of association between the observations and forecast for the entire SOP1, whereas it had a smaller value for only the IOP days.

For both models, the smallest value of PCC was for IOP 9, because they overestimated the number of strong precipitation events, especially ALADIN $2 \mathrm{~km}$, which can be seen 

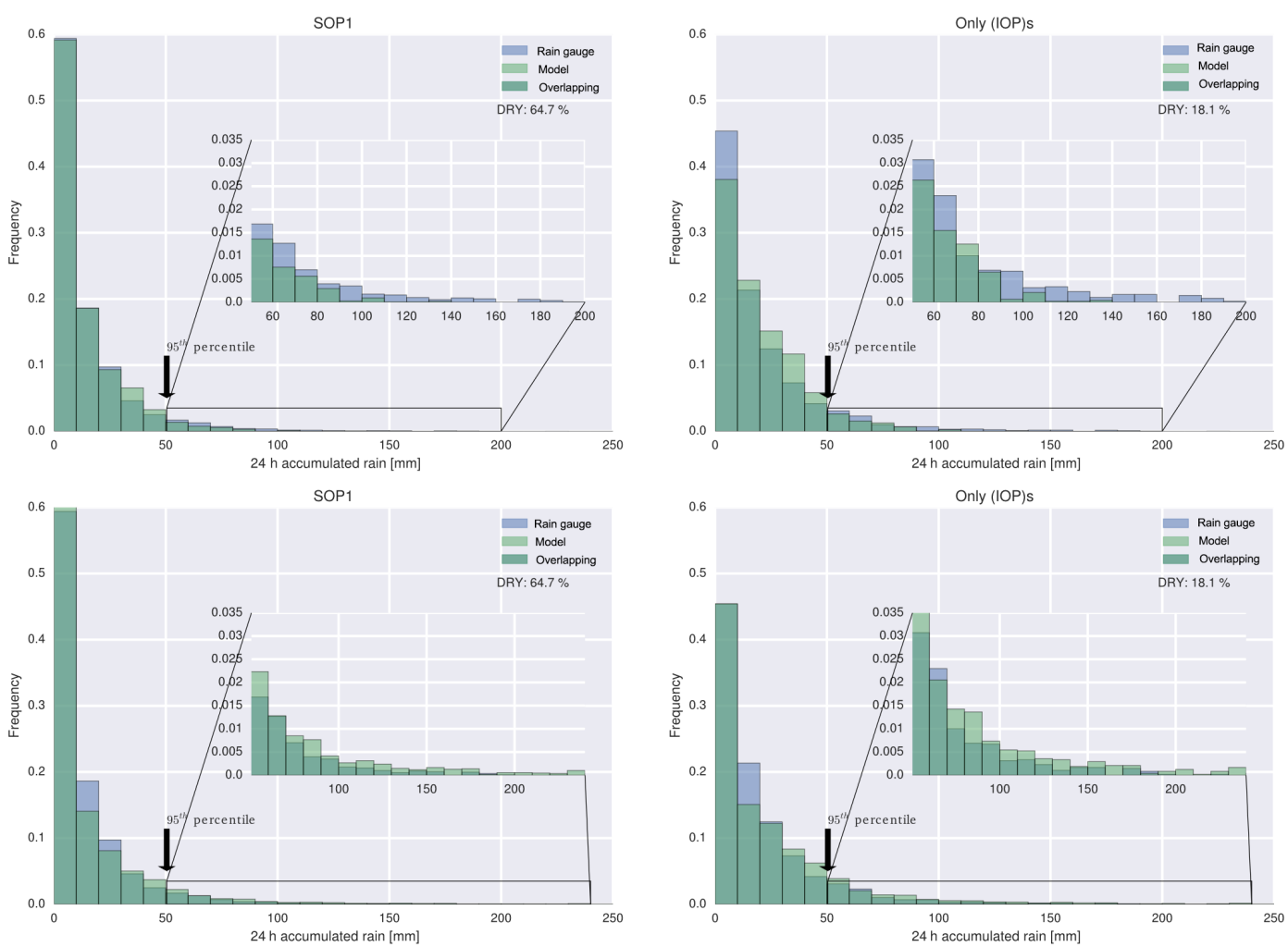

Figure 10. Normalized histogram of rain events ( $24 \mathrm{~h}$ accumulated precipitation on rain gauge station greater or equal $0.2 \mathrm{~mm} / 24 \mathrm{~h}$ ) for the entire SOP1 period (5 September to 6 November 2012) (left column) and for days of selected IOPs within the same period (right column). The first histogram bin starts from $0.2 \mathrm{~mm}$, whereas the number of dry days for a given period is indicated on the graph. The location of the 95th percentile of the SOP1 rain events distribution $(50.42 \mathrm{~mm} / 24 \mathrm{~h})$ is shown. The area of the histogram after the 95 th percentile is enlarged and shown as an inset to improve readability. The frequency of the precipitation events for rain gauge is coloured in blue and in light green for the model, whereas dark green indicates the overlapping of the model and rain gauge data. First row: ALADIN 8 km. Second row: ALADIN $2 \mathrm{~km}$ upscaled to an ALADIN $8 \mathrm{~km}$ grid.

from the much higher FBIAS than that from the ALADIN $8 \mathrm{~km}$ model. Comparing the performances of the two ALADIN models, it can be observed that ALADIN $2 \mathrm{~km}$ had higher levels of association between the observations and forecasts for IOP13 and IOP19 compared to ALADIN $8 \mathrm{~km}$. For IOP13, ALADIN $2 \mathrm{~km}$ was relatively more accurate in all three categories, which can be seen from the higher values of the critical success index (CSI). For IOP19, the FBIAS values show that ALADIN $2 \mathrm{~km}$ overestimated the frequency of strong precipitation, but at the same time it was relatively more accurate for the other two categories (higher CSI). For the dry category, ALADIN $2 \mathrm{~km}$ had better scores for almost all the selected cases (higher CSI; FBIAS closer to 1). For medium precipitation, ALADIN $8 \mathrm{~km}$ had better scores, except for IOP13 and IOP19. For the strong category, the scores show that ALADIN $2 \mathrm{~km}$ tended to overestimate the frequency of strong events, whereas ALADIN $8 \mathrm{~km}$ tended to underestimate the frequency of strong events, with the sole exception of IOP19, for which both models overestimated the number of strong precipitation events (especially ALADIN $2 \mathrm{~km})$.

\section{IOP2 over the north-eastern Adriatic TA}

Although the Adriatic TA was not part of the extensive experimental activity during SOP 1 , many events that affected the western Mediterranean also expanded into the Adriatic area. During IOP2, in the late evening hours of 12 September, an episode with very heavy rainfall over only a few hours was recorded over the city of Rijeka, on the northern coast of Kvarner Bay in the eastern Adriatic Sea and its mountainous hinterland of Gorski Kotar. According to a report from the Municipal Water and Sewer Company of the city of Rijeka, some major city roads became rivers and streams, sewage manhole covers were discharged, massive caps flew into the air up to $2 \mathrm{~m}$, and a spate of them were then carried up to $100 \mathrm{~m}$ from their shafts.

Ferretti et al. (2014) described IOP2 in north-eastern Italy (NEI) and analysed the meteorological characteristics and synoptic situation. A shallow orographic cyclone developed on the lee side of the Alps, extending from the Genoa Gulf to the northern Adriatic. Simultaneously, with the Genoa cyclogenesis, a twin type of cyclone (Horvath et al., 2008) devel- 
oped in the northern Adriatic (Fig. 11a and b). The Croatian coast of the northern and the central Adriatic was influenced by the strong moist south-western flow on the leading side of the cyclone(s). The air was moist due to south-west advection and evaporation from the Mediterranean. Below $2 \mathrm{~km}$, there was strong convergence over the northern Adriatic. Due to its specific position deep in Kvarner bay, which is open from the south-west and, at the same time, in the very pedestal of the Velebit mountain chain, the city of Rijeka and its surroundings have geographic preconditions for pronounced convection, with extensive precipitation under such specific synoptic conditions (e.g. Ivančan-Picek et al., 2003).

During the day in the late afternoon, cold air erupted along the Alpine slopes and, together with the passage of the cold front over NEI and the north-eastern Adriatic Sea, resulted in intensive convective processes.

\subsection{Extreme value analysis of the short-term precipitation maxima}

The spatial distribution of the daily rainfall amounts for the IOP2 rain episode indicates that the largest amounts fell over the city of Rijeka ( $220 \mathrm{~mm}$ at the Rijeka meteorological station, which is located $120 \mathrm{~m}$ above sea level) and the surrounding mainland hilly slopes and mountainous hinterland. According to the rainfall data recorded by ombrograph at the Rijeka meteorological station, a more detailed insight into the temporal rainfall distribution during the short-term interval of this heavy rainfall event is possible (Fig. 12). The rainfall episode that occurred during the $6 \mathrm{~h}$ period between $6 \mathrm{pm}$ and midnight was most intense between 9 and $11 \mathrm{pm}$. The maximum 20, 30, 40, 50, 60 and $120 \mathrm{~min}$ rainfall totals, which would have been the most intense part of the rainfall episode, have not been recorded at the Rijeka station since the beginning of measurements in 1958 (Table 5). The rainfall intervals of 20,30 and 40 min were especially intense and could be expected once in a more than a thousand, a few hundred and a hundred years, respectively, and correspond to an extraordinarily rare event as computed over the period 19582011 (Patarčić et al., 2014). The maximum amounts that fell in the 2 and $4 \mathrm{~h}$ intervals could be expected every forty and fifty years, respectively.

\subsection{Observational analysis}

On 12 September 2012, a sequence of convective events hit the north-eastern part of Italy and, in particular, the eastern part of the Veneto region and the plain of the Friuli Venezia Giulia region. During that day, at least two of the events could be classified as supercells, and the first one was also associated with heavy hail (Manzato et al., 2015; Miglietta et al., 2016). After a few hours, a third storm system that resembled a squall line, although of limited dimensions, swept over the area.
Table 5. Annual maximal precipitation amounts $\left(R_{\max }\right)$ recorded in different intervals $t$ ( $\mathrm{min}$ ) throughout the period 1958-2011 and during the heavy rainfall event on 12 September 2012 at Rijeka and their return values $(T)$ according to the GEV distribution applied to the period 1958-2011.

\begin{tabular}{lrrrr}
\hline \multirow{2}{*}{$t(\min )$} & \multicolumn{1}{c}{$1958-2011$} & 12 Sep 2012 & $T_{1958-2011}$ \\
\cline { 2 - 3 } & $\begin{array}{r}R_{\max } \\
(\mathrm{mm})\end{array}$ & $\begin{array}{r}T \\
(\mathrm{yr})\end{array}$ & & \\
\hline $5 \mathrm{~min}$ & 19.3 & 50 & 14.5 & 7 \\
$10 \mathrm{~min}$ & 29.2 & 54 & 24.6 & 12 \\
$20 \mathrm{~min}$ & 40.2 & 63 & 46.7 & $>1000$ \\
$30 \mathrm{~min}$ & 55.5 & 69 & 63.7 & 415 \\
$40 \mathrm{~min}$ & 67 & 48 & 74.8 & 130 \\
$50 \mathrm{~min}$ & 77.8 & 40 & 80.8 & 62 \\
$60 \mathrm{~min}$ & 86.4 & 40 & 87.4 & 43 \\
$120 \mathrm{~min}$ & 138.9 & 38 & 141.1 & 40 \\
$4 \mathrm{~h}$ & 194.9 & 80 & 171.8 & 52 \\
$6 \mathrm{~h}$ & 252.5 & 103 & 181.5 & 36 \\
$12 \mathrm{~h}$ & 317.3 & 214 & 200.9 & 37 \\
$18 \mathrm{~h}$ & 324.7 & 228 & 205.3 & 29 \\
$24 \mathrm{~h}$ & 324.7 & 232 & 208.3 & 25 \\
\hline
\end{tabular}

EUMETSAT was conducting its first experimental $2.5 \mathrm{~min}$ rapid scan with the MSG-3 satellite, and data are available from early morning until 09:00 UTC of the IOP2 day. Unfortunately, the MSG-3 satellite (renamed Meteosat-10) experimental rapid scan data, which have intervals of $2.5 \mathrm{~min}$, are available only until 09:00 UTC on 12 September 2012.

The nearby areas of Istria and Rijeka first received rain in the early afternoon, which soon stopped before the torrential rain in the evening between 21:00 and 23:00 UTC. This rain was connected to a third storm over Italy (as discussed in Manzato et al., 2015), which was an elongated storm moving along the coast of the northern Adriatic. Convection developed over the northern Adriatic, and warm and moist advection produced intensive precipitation triggered by the orography inland.

Satellite data show that cumulonimbus clouds formed (Fig. 13). This intensive rainfall band reached Trieste and Slovenia according to the radar data (not presented) and merged with the rainfall band that formed above Trieste at 18:00 UTC. Another rainfall band formed above the Istria peninsula at 19:30 UTC. Intensive rainfall spread to Rijeka and persisted there for several hours. During that time, other rainfall bands formed and moved over Rijeka, intensifying the precipitation and prolonging the period of high precipitation intensity.

According to the hourly amounts, the largest precipitation intensity occurred from $21: 00$ to $22: 00$ UTC $(85.3 \mathrm{~mm} / \mathrm{h})$, with 20.6 and $51.7 \mathrm{~mm} \mathrm{~h}^{-1}$ in the previous and following hour (Fig. 12).

Sounding data measured at Zadar-Zemunik, which is located approximately $150 \mathrm{~km}$ south-south-east of the area 

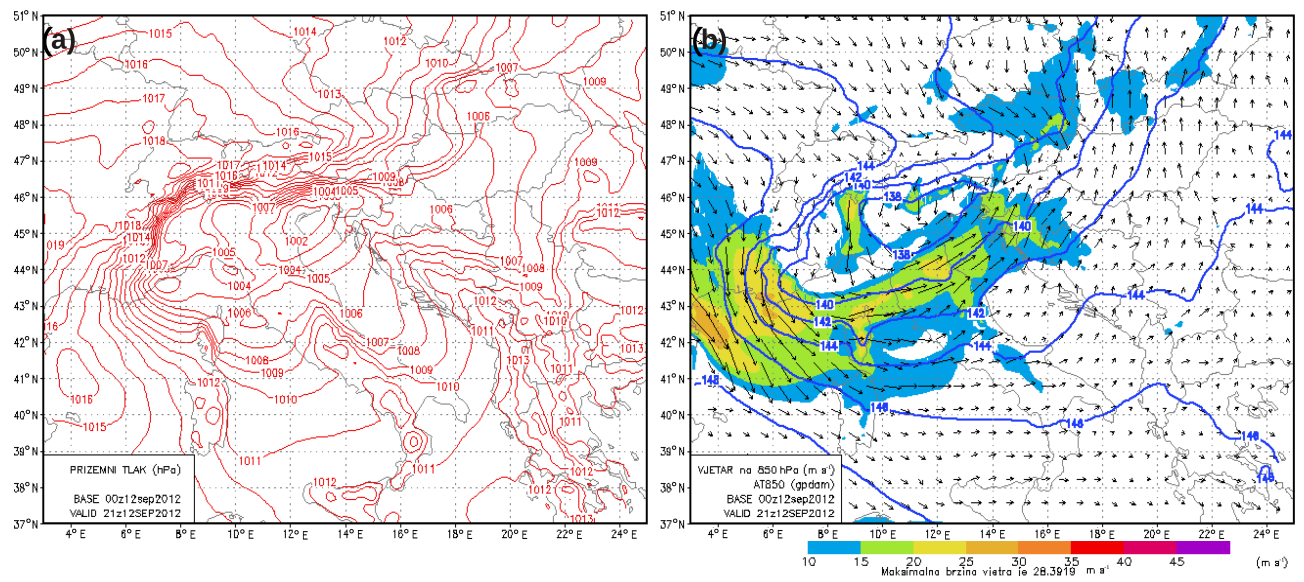

Figure 11. Mean sea level pressure (a) and $850 \mathrm{hPa}$ geopotential height (blue isolines), wind speed (background shading) and direction (vectors) (b) according to the ALADIN model operational forecast on 21:00 UTC 12 September 2012 (starting from the 00:00 UTC analysis of the same day).

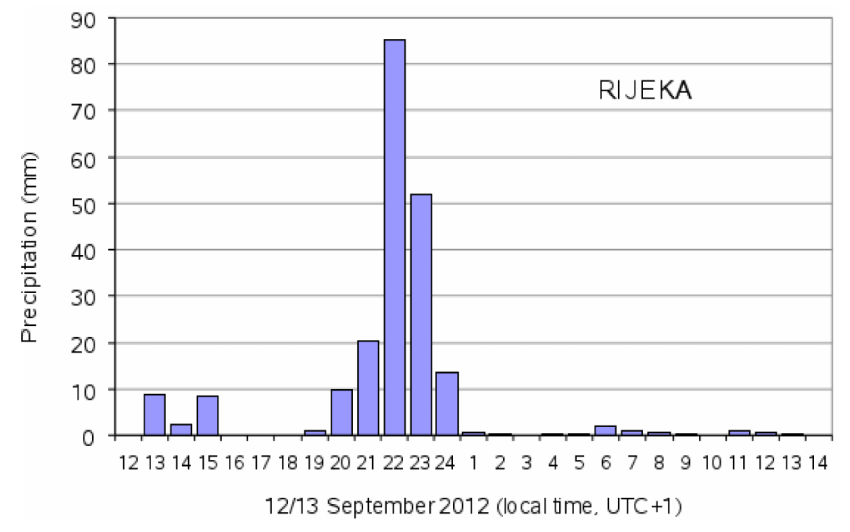

Figure 12. Hour precipitation amounts recorded from $1 \mathrm{pm}$ on 12 September 2012 to 1 pm on 13 September 2012 at the Rijeka meteorological station.

where the largest rainfall was recorded, can provide information on the vertical structure of the troposphere. Although the thermodynamic profile characteristics are not completely representative of the preconvective environment over the study area, this is the only available sounding data for the eastern Adriatic. The soundings featured a low-level moist atmospheric layer from the surface to approximately $850 \mathrm{hPa}$ that was connected with SE jugo wind, confirming that there was a suitable environment for strong convective activity (not presented). The winds strengthened throughout the troposphere, and the highest intensity was observed at $400 \mathrm{hPa}$.

\subsection{Operational model forecasts}

During SOP1, DHMZ made the operational forecast available from the ALADIN operational forecast model at $8 \mathrm{~km}$ and non-hydrostatic $2 \mathrm{~km}$ horizontal resolutions (Sect. 2.2). The two versions of the ALADIN model are compared here,

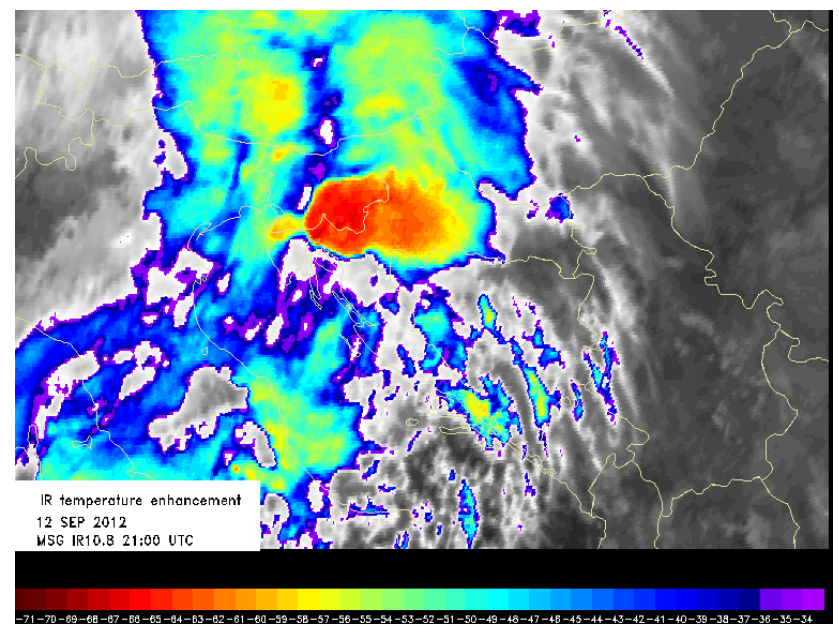

Figure 13. IR temperature enhanced satellite image for 21:00 UTC on 12 September 2012, which was the operational MSG product used in DHMZ at the time.

and the comparison shows the capability for forecasting intense convective activity in the area.

The short-range forecasts well reproduced the large-scale and mesoscale features responsible for the event (Fig. 11). The low-level wind field was dominated by two low-level jet streams (LLJs) and caused the appearance of the low-level wind convergence over the northern Adriatic that was associated with the main Genoa cyclone (Fig. 11b). In this case, the performance of the model was rather successful in comparison with the ECMWF reanalysis (not presented). One south-westerly LLJ was elongated from Italy towards the mid-Adriatic and carried warm and humid Mediterranean air to the Adriatic Sea. Another north-easterly LLJ (bora wind) was modified and intensified by the pressure gradient across the southern flank of the Alps (Fig. 11a). This convergence 

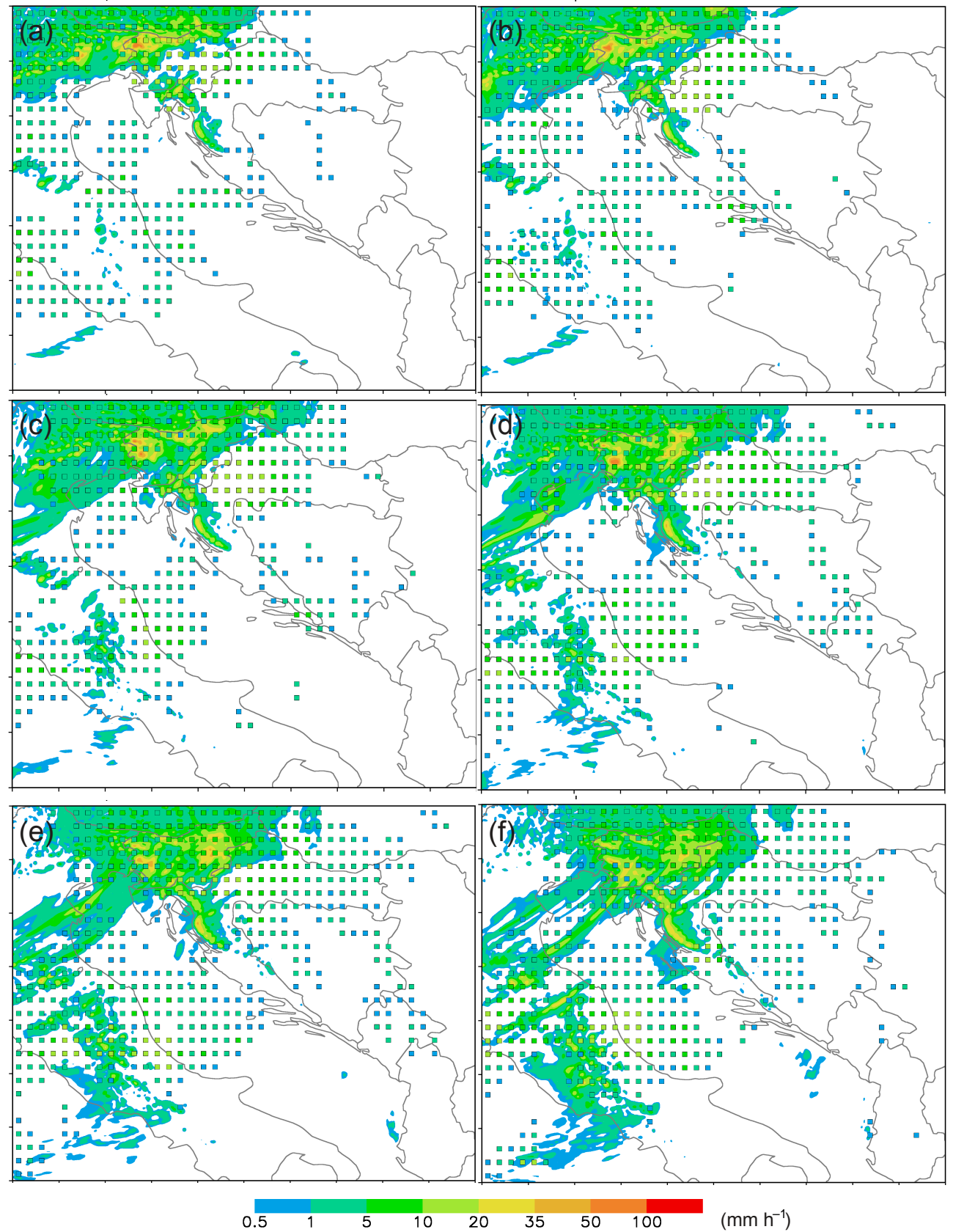

Figure 14. High-resolution forecast of hourly accumulated precipitation (shaded background) and TRMM 3B41RT precipitation estimates (squares) for (a) 19:00, (b) 20:00, (c) 21:00, (d) 22:00 and (e) 23:00 UTC on 12 September and (f) 00:00 UTC on 13 September 2012; this was the period of highest precipitation intensity. The satellite-derived precipitation data were used as provided by the Tropical Rainfall Measuring Mission (TRMM, Huffman et al., 2007); in particular, we used the hourly precipitation intensity data from the 3B41RT product.

was responsible for the convective triggering in the late afternoon. Although the mesoscale characteristics were correctly reproduced, the location and timing of the precipitation were not well predicted. The intensive precipitation event was predicted by both models, with precipitation close to or exceeding $100 \mathrm{~mm} / 24 \mathrm{~h}$ inland of Rijeka (Fig. 4), but the amount of precipitation was underestimated for the city of Rijeka, which lies on the coastline in all operational models, possibly due to an absence of the cold pool that formed after the showers in the early afternoon or the low-level wind from north-east that started earlier than in the model forecast.

The operational forecast set-up of the ALADIN $2 \mathrm{~km}$ resolution run overestimated the rainfall above the mountains (at least when compared to the $3 \mathrm{~B} 41$ products from 

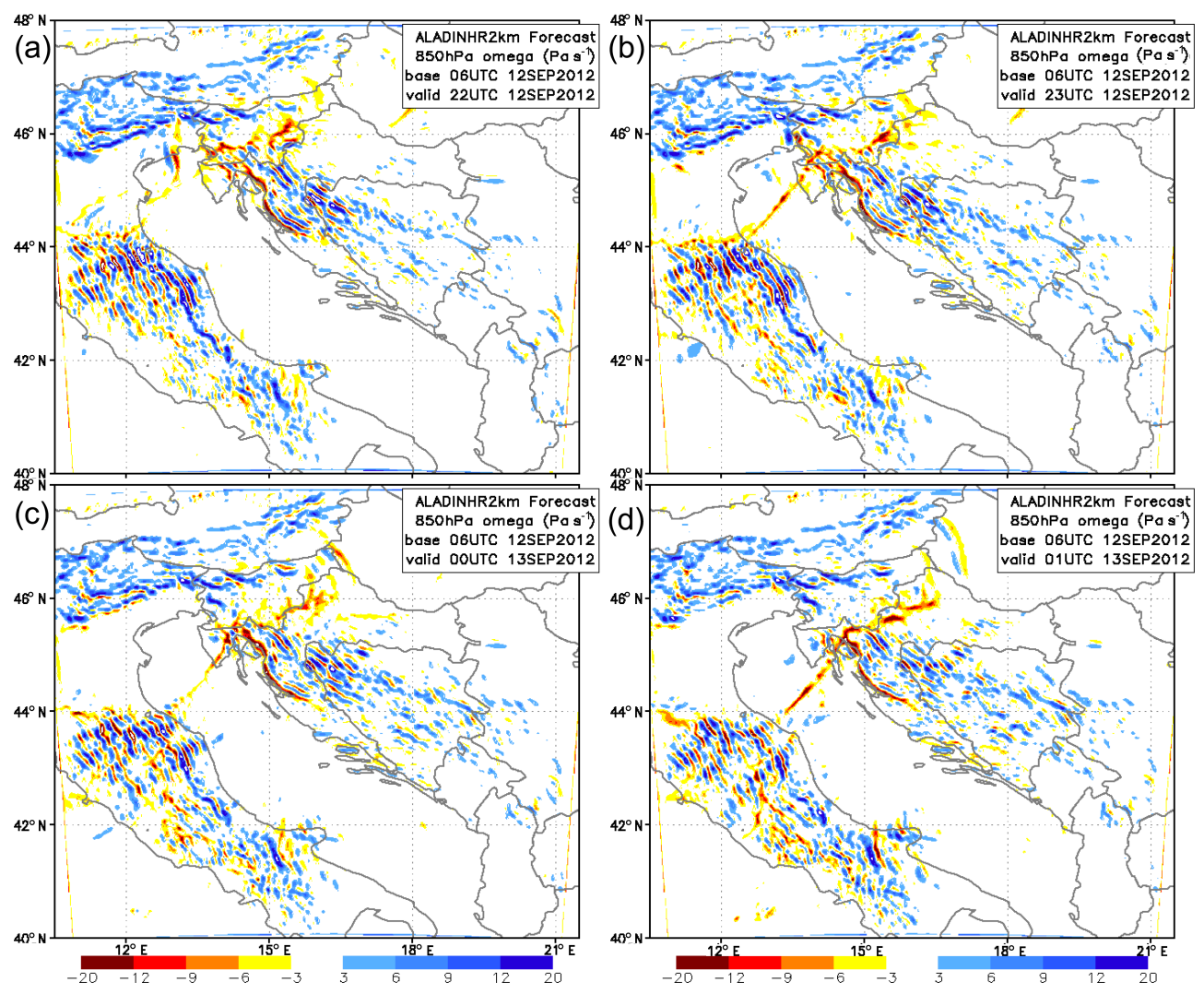

Figure 15. Vertical velocity omega $\left(\mathrm{Pa} \mathrm{s}^{-1}\right)$ at the $850 \mathrm{hPa}$ level from the operational $2 \mathrm{~km}$-resolution forecast for (a) 22:00 and (b) 23:00 UTC on 12 September and (c) 00:00 and (d) 01:00 UTC on 13 September 2012; upward motions are shown in shades of red, and downward motions are shown in blue.
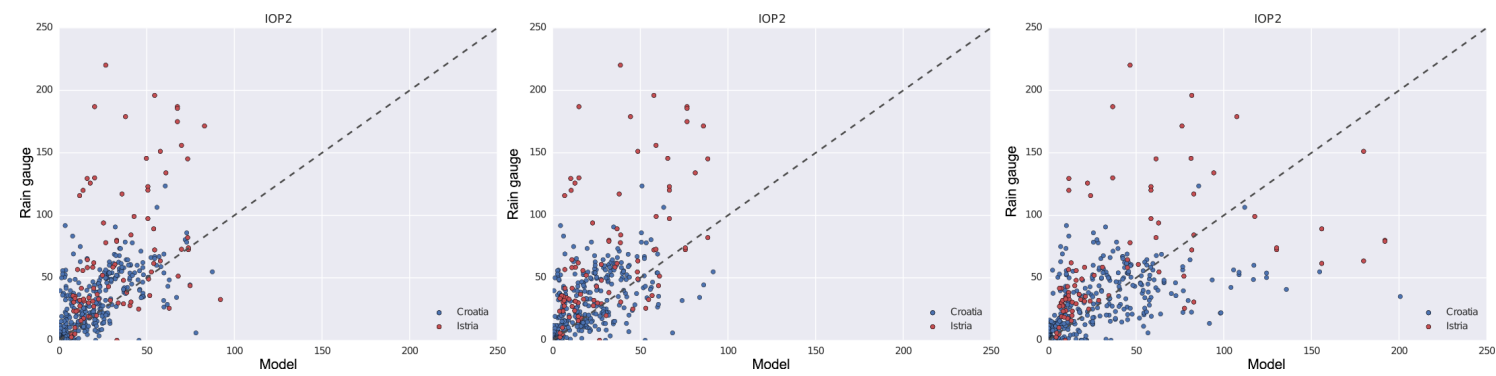

Figure 16. Scatter plot of $24 \mathrm{~h}$ accumulated precipitation from rain gauges over Croatia and the model equivalents from the ALADIN $8 \mathrm{~km}$ (left), ALADIN $8 \mathrm{~km}$ without data assimilation (middle), and ALADIN $2 \mathrm{~km}$ (right) models and from the point nearest the location of the rain gauge for IOP2. The locations from the Istria peninsula are marked in red.

the TRMM data server), but it was consequently closer to the extreme amounts measured in the Rijeka area (Fig. 14). Although the $3 \mathrm{~B} 41$ product is an estimate of precipitation intensity, which also suffers from errors, the rain over the southern Velebit mountains was overestimated, but was correct for the mountains inland of Rijeka. In the hours of peak precipitation intensity in Rijeka, the satellite measurement data-derived precipitation (TRMM 3B41RT product available from NASA's Giovanni web service) was also considerably lower than that measured in situ.
The high-resolution, non-hydrostatic operational forecast showed upward motions along the coastal mountains of Croatia that were associated with the convergence line and the rain band over the sea (Fig. 15). The wave of upward motion moved from the Po valley eastward and reached Rijeka area $1 \mathrm{~h}$ after the recorded maximum intensity in precipitation, and the model might, therefore, have been slightly later than the real weather events. A permanent wave formed over the southern Velebit (and several other mountains) and persisted throughout the night. The wave was responsible for 
$24 \mathrm{~h}$ accumulated precipitation (2012-09-12 06UTC - 2012-09-13 06UTC)

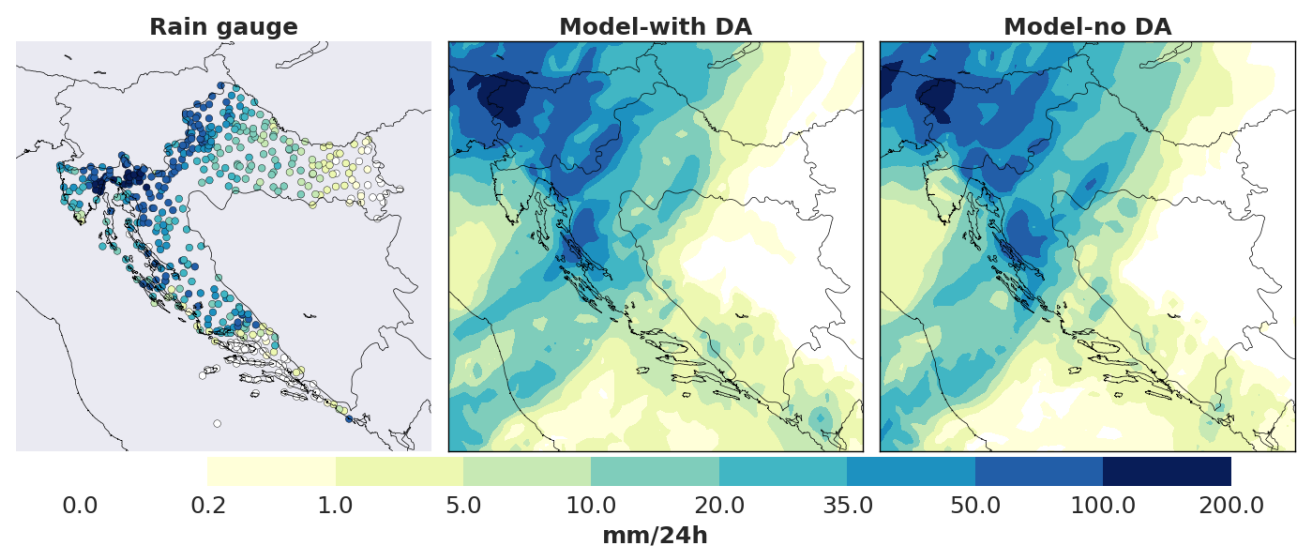

Figure 17. The $24 \mathrm{~h}$ accumulated precipitation from 12 September 06:00 UTC until 13 September 06:00 UTC (IOP12). Left: rain gauge measurement. Middle: ALADIN $8 \mathrm{~km}$ operational forecast with data assimilation. Right: ALADIN $8 \mathrm{~km}$ forecast without data assimilation.

triggering the precipitation, and its intensity was probably overestimated. Apparently, small but tall topographic obstacles can trigger too much precipitation; this issue must still be solved.

Figure 16 presents a scatter plot of the $24 \mathrm{~h}$ accumulated precipitation from rain gauges over Croatia and the forecast values from the ALADIN model taken from the nearest grid points for IOP2. The ALADIN $8 \mathrm{~km}$ model underestimated precipitation and forecasted up to $92 \mathrm{~mm} / 24 \mathrm{~h}$ of rainfall, whereas the measurements reached $220 \mathrm{~mm} / 24 \mathrm{~h}$. Much better results were obtained from the ALADIN $2 \mathrm{~km}$ model; the values predicted by the model reached $200 \mathrm{~mm} / 24 \mathrm{~h}$. A location error is also evident for both models, especially for the area where the most intense precipitation occurred (Istria peninsula; red dots), but it was smaller for the ALADIN $2 \mathrm{~km}$ model. The medium precipitation amounts were better forecast than the strong precipitation amounts but were still slightly overestimated for the ALADIN $8 \mathrm{~km}$ model, and much more spread can be seen for the ALADIN $2 \mathrm{~km}$ model, with both overestimation and underestimation, but with better results for the Istria peninsula. From Tables 3 and 4, it can be observed that ALADIN $2 \mathrm{~km}$ was relatively more accurate (higher CSI) for the dry and strong categories, but not for the medium category, than ALADIN $8 \mathrm{~km}$. FBIAS was better for ALADIN $2 \mathrm{~km}$ for the medium category in addition to the dry and strong categories compared to the ALADIN $8 \mathrm{~km}$ results.

\subsection{Influence of the data assimilation}

Because the lack of model skill when simulating HPEs could be partially attributed to imperfect initial conditions, we performed several NWP experiments to assess the impact of data assimilation on the IOP2 forecast accuracy. Observations used in the operational data assimilation system include ground station observations ( $2 \mathrm{~m}$ temperature, $2 \mathrm{~m}$ relative humidity, pressure), radio soundings (temperature, humidity, wind components), aircraft-based observations (temperature, wind components), wind components derived from a cloud motion detection process based on the measurements of geostationary satellites and brightness temperature from geostationary and polar satellites.

A comparison of the measurements with an operational forecast and simulations without data assimilation is shown in Fig. 17. The rain gauges showed that an elongated area of stronger precipitation along the Croatia-Slovenia border was present, and that pattern was better forecasted by the operational run that incorporated data assimilation. In addition, higher amounts of the medium rain category over the Istria peninsula were found in the operational run, which better accorded with measurements. This can also be seen in Fig. 16, where for the run with data assimilation the points are less scattered, and more points with higher values of precipitation over Istria are present. The maximum recorded around the town of Rijeka was not adequately represented by either model.

The verification measures (Table 3 ) show that the simulation with data assimilation produced slightly better results. The scores for the entirety of Croatia show that the strong precipitation category results were improved for the operational run $(\mathrm{CSI}=0.28)$ compared to the run without data assimilation $(\mathrm{CSI}=0.23)$. In addition, PCC showed that the model and observations for the run with data assimilation were better associated. The impact of data assimilation was rather small, but it yielded an improvement in the $24 \mathrm{~h}$ precipitation forecast. It should be considered that for the selected case, better results were obtained with the higher-resolution model and that the data assimilated in the operational ALADIN $8 \mathrm{~km}$ model was mainly synoptic. Thus, implementing data assimilation in the higher-resolution model and adding additional high-resolution temporal and/or spatial data to the 
data assimilation system are apparently good ways of further enhancing operational forecasts.

\section{Summary and conclusions}

In this paper, an overview of the IOPs that affected the Adriatic TA during the SOP1 HyMeX campaign (5 September to 6 November 2012) is presented. During SOP1, 20 IOPs were declared, and 8 of those events affected the EOP Adriatic TA. All the events produced localized heavy precipitation and often were properly forecast by the available ALADIN operational model, but uncertainties existed in the exact prediction of the amounts, precise times and locations of maximum intensity. The total precipitation amounts for SOP1 exceeded the corresponding climatology for the Adriatic TA. The precipitation maximum (more than $1.000 \mathrm{~mm}$ in 61 days at some locations) was recorded in the northern Adriatic (city of Rijeka) and its mountainous hinterland of Gorski Kotar. This region experiences climatic maxima of annual precipitation greater than $3.000 \mathrm{~mm}$ on average. The analysis was performed primarily using measurements from the operational meteorological network maintained by the Meteorological and Hydrological Service of Croatia.

There were 15 days when the accumulated rainfall at least one rain gauge in the Adriatic TA exceeded $100 \mathrm{~mm}$ in $24 \mathrm{~h}$. Most of the HPEs contained similar ingredients and synoptic settings but had different intensities: an extensive deep upper level, cyclone strengthening over the Mediterranean (or developing over the Gulf of Genoa, Lyon or the Tyrrhenian Sea), a strong south-westerly low-level jet stream that advects moist and warm air towards the orographic obstacles along the Mediterranean coastline and destabilizes the atmosphere as the strong wind picks up moisture from the sea.

The verification of the operational precipitation forecasts during SOP 1 suggests the operational ALADIN model with $8 \mathrm{~km}$ grid spacing may be useful for issuing early warnings of severe precipitation events in the region. For most of the events, the precipitation forecast and measurements were highly associated. From the verification statistics and different precipitation-related figures, it can be seen that an obvious limitation of the ALADIN $8 \mathrm{~km}$ model is its inability to produce high amounts of precipitation and its tendency to underestimate the frequency of dry events. Both issues can be ameliorated using a non-hydrostatic model at a higher resolution (ALADIN $2 \mathrm{~km}$ ). Nevertheless, the exact precipitation amounts were not always well simulated. The verification methods used in this work are limited because the utilized score calculation method is a point-based comparison and is thus prone to location errors, and other methods that are used are based on subjective comparisons of different precipitation plots. A next step would be to implement an objectbased verification method, e.g. SAL (structure-amplitudelocation) (Wernli et al., 2008), which could provide more objective verification measures, but for this local spatial precipitation analysis, the method must first be developed.

During IOP2 on 12 September 2012, several thunderstorms formed, including a supercell and a possible tornado outbreak. The warm and moist air advected in the low levels over the Adriatic (and Mediterranean before that) fed the storms, but one storm apparently produced downdraughts which would in turn have formed a convergence zone with moist flow from the sea and triggered the next storm. The intensive precipitation event in Rijeka and the surrounding area resulted from the influence of the coastal mountains on the movement of a convergence line. The atmosphere contained a lot of moisture and was nearly saturated up to $6 \mathrm{~km}$. The air flow converged above northern Adriatic in the layer up to $2 \mathrm{~km}$. The convergence line moved south-eastward, whereas rainfall intensified in the Rijeka area due to local terrain. The peak intensity was underestimated by the model forecast.

Such a chain of events poses a challenge with respect to predictability. The fact that the surrounding mountains represent physical obstacles that modified the flow and determined the position of the convergence zones made forecasting the location of such a chain of events more predictable. An abundance of available real-time measured data, including radar measurements, aircraft data and targeted radio soundings, can improve the initial conditions for the NWP models. The ambiguities in the sea surface fluxes, which were an important source of energy for this event, could be the factor that limits the abilities of deterministic forecasts.

The numerical sensitivity experiments with respect to the mesoscale data assimilation suggested the precipitation forecast during IOP2 was improved by using data assimilation to produce initial conditions, compared to forecasts in which initial conditions were derived from the global model data. The use of mesoscale data assimilation for initial conditions enhanced the precipitation structure and intensity. This is also evident given the improvement in the objective verification measures, including the critical success index and PCC. The data assimilation system could be further enhanced by using additional observations, e.g. radar and ground-based GNSS (Global Navigation Satellite System) data, shorter data assimilation cycles (e.g. 3 instead of $6 \mathrm{~h}$ ) or a $\mathbf{B}$ matrix computed using more advanced methods (an ensemble B matrix instead of NMC based). Work also continues to implement a data assimilation system to a higher-resolution model.

Furthermore, the operational non-hydrostatic model at a $2 \mathrm{~km}$ grid spacing was able to predict the intensity of an HPE more accurately than the hydrostatic model at an $8 \mathrm{~km}$ grid spacing. Nevertheless, a higher-resolution forecast can misplace the position of the peak precipitation and overestimate the precipitation over narrow but high mountains such as the southern Velebit. This may be an artefact of the excessive sea surface temperature in the model in that region. These results suggest that precipitation forecasts in the Adriatic TA may be 
improved both by using mesoscale data assimilation and by decreasing the grid spacing of the model.

Heavy precipitation over the Adriatic area is often associated with sirocco (jugo) or bora winds and thus involves intense air-sea interactions. IOP4 provided an excellent example of very intensive heat loss caused by a strong bora wind. In that case, the control simulation run was more realistic with colder SSTs and was generally drier than the operational run with warmer SSTs. IOP4 illustrates the need for further improvements of the role of the SST and surface (latent and sensible) heat fluxes over the Adriatic Sea, which attain large values during strong bora events. However, a more detailed analysis of the impact of SST on precipitation is ongoing.

This paper, therefore, highlights the need to enforce an intensive observation period in the future over the Adriatic region to better understand the relevant processes, validate the simulated mechanisms and improve numerical forecasts via data assimilation and improvements in model representations of moist processes and sea-land-atmosphere interactions. There is also a need for collaborative efforts within the Italian (and other) HyMeX scientific and forecast communities to achieve a better understanding of the complex processes that cause extreme events over the Adriatic region.

\section{Data availability}

Research data and operational DHMZ data from 5 September to 6 November 2012 used in this paper are available in the HyMeX database (http://mistrals.sedoo.fr/HyMeX/). The additional data from the DHMZ observational network are available on request at (http://meteo.hr/index_en.php). 


\section{Appendix A}

The indices used in the statistical analysis of verification quality are briefly described and defined below. All the indices mentioned in Tables 2, 3 were calculated from a $3 \times 3$ contingency table, the general form of which is shown in Table A1. A contingency table with three categories (dry, medium and strong) was defined according to the amount of $24 \mathrm{~h}$ accumulated precipitation (Table A1). An event was defined as dry if the $24 \mathrm{~h}$ accumulated precipitation on the rain gauge station was less than or equal to $0.2 \mathrm{~mm} / 24 \mathrm{~h}$. The border between the medium and strong categories was defined as the 95 th percentile $(50.42 \mathrm{~mm} / 24 \mathrm{~h})$ of measured $24 \mathrm{~h}$ accumulated precipitation during the SOP1 period, but with dry events excluded.

The formulas for calculating the verification measures used in Tables 2 and 3 are provided here, where the subscripts $\mathrm{D}, \mathrm{M}$ and $\mathrm{S}$ indicate dry, medium and strong categories.

BASE RATE (BR) provides information on the observed event frequency. It does not depend on the forecasted values.

$\mathrm{BR}_{\mathrm{D}}=\frac{m}{p} ; \mathrm{BR}_{\mathrm{M}}=\frac{n}{p} ; \mathrm{BR}_{\mathrm{S}}=\frac{o}{p} ;$

FREQUENCY BIAS (FBIAS) indicates how well the forecast frequency of an event corresponds to the observed frequency of the event. FBIAS $=1$ for a perfect score. If FBIAS $>1$, the model has a tendency to overforecast events, whereas FBIAS $<1$ indicates that the model has a tendency to underforecast events.

FBIAS $_{\mathrm{D}}=\frac{d}{m} ;$ FBIAS $_{\mathrm{M}}=\frac{h}{n} ;$ FIAS $_{\mathrm{S}}=\frac{l}{o} ;$

CRITICAL SUCCESS INDEX (CSI) measures the relative accuracy of a forecast. It is defined as the ratio of the number of correct forecasts of an event for some category and the sum of the number of correct forecasts of the event in that category, the number of events that were forecasted in that category and that were not observed and the number of observed events that were not forecast in that category. CSI has values in the interval $[0,1]$, and 1 is a perfect forecast.

$\operatorname{CSI}_{\mathrm{D}}=\frac{a}{m+d-a} ; \operatorname{CSI}_{\mathrm{M}}=\frac{f}{n+h-f} ; \operatorname{CSI}_{\mathrm{S}}=\frac{k}{o+l-k}$
Table A1. General form of a multicategory $(3 \times 3)$ contingency table with a marginal distribution.

\begin{tabular}{llcccc}
\hline & & \multicolumn{4}{c}{ Observations } \\
\cline { 3 - 6 } & & Dry & Medium & Strong & $\sum$ \\
\hline \multirow{5}{*}{ Forecast } & Dry & $a$ & $b$ & $c$ & $d$ \\
& Medium & $e$ & $f$ & $g$ & $h$ \\
& Strong & $i$ & $j$ & $k$ & $l$ \\
& $\sum$ & $m$ & $n$ & $o$ & $p$ \\
\hline
\end{tabular}

POLYCHORIC CORRELATION COEFFICIENT (PCC)

represents a measure of the association between an observation and forecast in the contingency table. The main idea is to make appropriate transformations of forecasted and observed values together with category thresholds and then to seek the parameter PCC of the bivariate density function for which the volumes of the discretized bivariate distribution is equal to the corresponding joint probabilities of the contingency table, with the assumption that their joint probability density function is bivariate normal. For contingency tables with more than two categories, several methods for estimating PCC exist. In this work, the maximum likelihood method (Olsson, 1979) was used. Additional information on using PCC for the verification of meteorological fields can be found in Juras and Pasarić (2006). PCC has values in the interval $[-1,1]$. 
Acknowledgements. This work is a contribution to the HyMeX programme. The authors are grateful to the participating institutions for providing the measurement and model data. This work is partially supported by the HyMeX-COOP project (ENVIMED regional programme) and IPA2007/HR/16IPO/001-040510 grant. The authors would also like to thank Jean-Francois Geleyn (deceased), the former project manager of ALADIN, for his ideas, energy, drive and persistence, which made us an active party in the development of a state of the art model system and enabled us to participate in such an important research programme. We thank Marjana Gajić-Čapka for her precipitation extreme value analysis. We thank Iris Odak Plenković for providing valuable advice and suggestions regarding precipitation verification. The authors are grateful to NASA for providing valuable satellite-derived products through the GIOVANNI web interface and the TRMM, OMI and MODIS scientists and developers.

Edited by: V. Kotroni

Reviewed by: two anonymous referees

\section{References}

Aladin International Team: The ALADIN project Mesoscale modelling seen as basic tool for weather forecasting and atmospheric research, WMO Bull., 46, 317-324, 1997.

Bénard, P., Vivoda, J., Mašek, J., Smolíková, P., Yessad, K., Smith, C., Brožková, R., and Geleyn, J.-F.: Dynamical kernel of the Aladin-NH spectral limited-area model: Revised formulation and sensitivity experiments, Q. J. Roy. Meteor. Soc., 136, 155169, doi:10.1002/qj.522, 2010.

Buzzi, A. and Foschini, L.: Mesoscale Meteorological Features Associated with Heavy Precipitation in the Southern Alpine Region, Meteorol. Atmos. Phys., 72, 131-146, doi:10.1007/s007030050011, 2000.

Buzzi, A. and Tibaldi, S.: Cyclogenesis in the lee of the Alps: A case study, Q. J. Roy. Meteor. Soc., 104, 271-287, doi:10.1002/qj.49710444004, 1978.

Catry, B., Geleyn, J.-F., Tudor, M., Benard, P., and Trojakova, A.: Flux-conservative thermodynamic equations in a massweighted framework, Tellus A, 59, 71-79, doi:10.1111/j.16000870.2006.00212.x, 2007.

Courtier, P., Andersson, E., Heckley, W., Vasiljevic, D., Hamrud, M., Hollingsworth, A., Rabier, F., Fisher, M., and Pailleux, J.: The ECMWF implementation of three-dimensional variational assimilation (3d-Var). I: Formulation, Q. J. Roy. Meteor. Soc., 124, 1783-1807, 1998.

Davies, H. C.: A lateral boundary formulation for multi-level prediction models, Q. J. Roy. Meteor. Soc., 102, 405-418, doi:10.1002/qj.49710243210, 1976.

Davolio, S., Mastrangelo, D., Miglietta, M. M., Drofa, O., Buzzi, A., and Malguzzi, P.: High resolution simulations of a flash flood near Venice, Nat. Hazards Earth Syst. Sci., 9, 1671-1678, doi:10.5194/nhess-9-1671-2009, 2009.

Davolio, S., Ferretti, R., Baldini, L., Casaioli, M., Cimini, D., Ferrario, M. E., Gentile, S., Loglisci, N., Maiello, I., Manzato, A., Mariani, S., Marsigli, C., Marzano, F. S., Miglietta, M. M., Montani, A., Panegrossi, G., Pasi, F., Pichelli, E., Pucillo, A., and Zinzi, A.: The role of the Italian scientific community in the first
HyMeX SOP: an outstanding multidisciplinary experience, Meteorol. Z., 24, 261-267, doi:10.1127/metz/2014/0624, 2015a.

Davolio, S., Stocchi, P., Benetazzo, A., Bohm, E., Riminucci, F., Ravaioli, M., Li, X.-M., and Carniel, S.: Exceptional Bora outbreak in winter 2012: Validation and analysis of high-resolution atmospheric model simulations in the northern Adriatic area, Dynam. Atmos. Oceans., 71, 1-20, 2015b.

Davolio, S., Volonte, A., Manzano, A., Pucillo, A., Cicogna, A., and Rerrario, M. E.: Mechanisms producing different precipitation patterns over north-eastern Italy: insights from HyMeXSOP1 and previous events, Q. J. Roy. Meteor. Soc., 142, 188205, doi:10.1002/qj.2731, 2016.

Dayan, U., Nissen, K., and Ulbrich, U.: Review Article: Atmospheric conditions inducing extreme precipitation over the eastern and western Mediterranean, Nat. Hazards Earth Syst. Sci., 15, 2525-2544, doi:10.5194/nhess-15-2525-2015, 2015.

Donlon, C. J., Martin, M., Stark, J., Roberts-Jones, J., Fiedler, E., and Wimmer, W.: The operational sea surface temperature and sea ice analysis (OSTIA) system, Remote Sens. Environ., 116, 140-158, 2012.

Doswell, C. A., Ramis, C., Romero, R., and Alonso, S.: A diagnostic study of three heavy precipitation episodes in the western Mediterranean, Weather Forecast., 13, 102-124, 1998.

Drobinski, P., Ducrocq, V., Alpert, P., Anagnostou, E., Béranger, K., Borga, M., Braud, I., Chanzy, A., Davolio, S., Delrieu, G., Estournel, C., Filali Boubrahmi, N., Font, J., Grubišić, V., Gualdi, S., Homar, V., Ivančan-Picek, B., Kottmeier, C., Kotroni, V., Lagouvardos, K., Lionello, P., Llasat, M. C., Ludwig, W., Lutoff, C., Mariotti, A., Richard, E., Romero, R., Rotunno, R., Roussot, O., Ruin, I., Somot, S., Taupier-Letage, I., Tintore, J., Uijlenhoet, R., and Wernli, H.: HyMeX: A 10-Year Multidisciplinary Program on the Mediterranean Water Cycle, B. Am. Meteorol Soc., 95, 1063-1082, doi:10.1175/BAMS-D-12-00242.1, 2014.

Ducrocq, V., Nuissier, O., Ricard, D., Lebeaupin, C., and Thouvenin, T.: A numerical study of three catastrophic precipitating events over western Mediterranean region (southern France), II: Mesoscale triggering and stationarity factors, Q. J. Roy. Meteor. Soc., 134, 131-145, doi:10.1002/qj.199, 2008.

Ducrocq, V., Braud, I., Davolio, S., Ferretti, R., Flamant, C., Jansa, A., Kalthoff, N., Richard, E., Taupier-Letage, I., Ayral, P.-A., Belamari, S., Berne, A., Borga, M., Boudevillain, B., Bock, O., Boichard, J.-L., Bouin, M.-N., Bousquet, O., Bouvier, C., Chiggiato, J., Cimini, D., Corsmeier, U., Coppola, L., Cocquerez, P., Defer, E., Drobinski, P., Dufournet, Y., Fourrié, N., Gourley, J. J., Labatut, L., Lambert, D., Le Coz, J., Marzano, F. S., Molinié, G., Montani, A., Nord, G., Nuret, M., Ramage, K., Rison, B., Roussot, O., Said, F., Schwarzenboeck, A., Testor, P., Van Baelen, J., Vincendon, B., Aran, M., and Tamayo, J.: HyMeX-SOP1, the field campaign dedicated to heavy precipitation and flash flooding in the northwestern Mediterranean, B. Am. Meteorol. Soc., 95, 1083-1100, doi:10.1175/BAMS-D-12-00244.1, 2014.

Duffourg, F. and Ducrocq, V.: Assessment of the water supply to Mediterranean heavy precipitation: a method based on finely designed water budgets, Atmos. Sci. Lett., 14, 133-138, doi:10.1002/asl2.429, 2013.

Ferretti, R., Pichelli, E., Gentile, S., Maiello, I., Cimini, D., Davolio, S., Miglietta, M. M., Panegrossi, G., Baldini, L., Pasi, F., Marzano, F. S., Zinzi, A., Mariani, S., Casaioli, M., Bartolini, G., Loglisci, N., Montani, A., Marsigli, C., Manzato, A., Pucillo, 
A., Ferrario, M. E., Colaiuda, V., and Rotunno, R.: Overview of the first HyMeX Special Observation Period over Italy: observations and model results, Hydrol. Earth Syst. Sci., 18, 1953-1977, doi:10.5194/hess-18-1953-2014, 2014.

Geleyn, J.-F.: Use of a modified Richardson number for parameterising the effect of shallow convection, J. Meteorol. Soc. Jpn., Special 1986 NWP Symposium Issue, 141-149, 1987.

Geleyn, J.-F. and Hollingsworth, A.: An economical analytical method for the computation of the interaction between scattering and line absorption of radiation, Contrib. Atmos. Phys., 52, $1-16,1979$.

Geleyn, J.-F.: Interpolation of wind, temperature and humidity values from model levels to the height of measurement, Tellus A, 40, 347-351, doi:10.1111/j.1600-0870.1988.tb00352.x, 1988.

Geleyn, J.-F., Bazile, E., Bougeault, P., Déqué, M., Ivanovici, V., Joly, A., Labbé, L., Piédelièvre, J.-P., Piriou, J.-M., and Royer, J.-F.: Atmospheric parametrization schemes in MétéoFrance's ARPEGE NWP model, in: Proceedings of the 1994 ECMWF seminar on physical parametrizations in numerical models, ECMWF, Reading, UK, 385-402, 1995.

Geleyn, J.-F., Bénard, P., and Fournier, R.: A general-purpose extension of the Malkmus band-model average equivalent width to the case of the Voigt line profile, Q. J. Roy. Meteor. Soc., 131, 2757-2768, doi:10.1256/qj.04.107, 2005a.

Geleyn, J.-F., Fournier, R., Hello, G., and Pristov, N.: A new "bracketing" technique for a flexible and economical computation of thermal radiative fluxes, scattering effects included, on the basis the Net Exchanged Rate (NER) formalism, WGNE Blue Book, $2005 b$.

Geleyn, J.-F., Váňa, F., Cedilnik, J., Tudor, M., and Catry, B.: An intermediate solution between diagnostic exchange coefficients and prognostic TKE methods for vertical turbulent transport, WGNE Blue Book, 2006.

Geleyn, J.-F., Catry, B., Bouteloup, Y., and Brožková, R.: A statistical approach for sedimentation inside a microphysical precipitation scheme, Tellus A, 60, 649-662, doi:10.3402/tellusa.v60i4.15375, 2008.

Gerard, L.: An integrated package for subgrid convection, clouds and precipitation compatible with the meso-gamma scales, Q. J. Roy. Meteor. Soc., 133, 711-730, doi:10.1002/qj.58, 2007.

Gerard, L. and Geleyn, J.-F.: Evolution of a subgrid deep convection parametrization in a limited-area model with increasing resolution, Q. J. Roy. Meteor. Soc., 131, 2293-2312, doi:10.1256/qj.04.72, 2005.

Gerard, L., Piriou, J.-M., Brožková, R., Geleyn, J.-F., and Banciu, D.: Cloud and precipitation parameterization in a meso-gamma scale operational weather prediction model, Mon. Weather Rev., 137, 3960-3977, doi:10.1175/2009MWR2750.1, 2009.

Giard, D. and Bazile, E.: Implementation of a new assimilation scheme for soil and surface variables in a global NWP model, Mon. Weather Rev., 128, 997-1015, doi:10.1175/15200493(2000)128<0997:IOANAS>2.0.CO;2, 2000.

Gospodinov, I., Spiridonov, V., and Geleyn, J.-F.: Second order accuracy of two-time-level semi-Lagrangian schemes, Q. J. Roy. Meteor. Soc., 127, 1017-1033, doi:10.1002/qj.49712757317, 2001

Grisogono, B. and Belušić, D.: A review of recent advances in understanding the meso- and microscale properties of the severe Bora wind, Tellus A, 61, 1-16, doi:10.1111/j.16000870.2008.00369.x, 2009.

Haugen, J. E. and Machenhauer, B.: A spectral limitedarea model formulation with time-dependent boundary conditions applied to the shallow-water equations, Mon. Weather Rev., 121, 2618-2630, doi:10.1175/15200493(1993)121<2618:ASLAMF>2.0.CO;2, 1993.

Hortal, M.: The development and testing of a new two-timelevel semi-Lagrangian scheme (SETTLS) in the ECMWF forecast model, Q. J. Roy. Meteor. Soc., 128, 1671- 1687, doi:10.1002/qj.200212858314, 2002.

Horvath, K., Fita, L., Romero, R., and Ivančan-Picek, B.: A numerical study of the first phase of a deep Mediterranean cyclone: Cyclogenesis in the lee of Atlas Mountains, Meteorol. Z., 15, 133-146, doi:10.1127/0941-2948/2006/0113, 2006.

Horvath, K., Lin, Y.-L., and Ivančan-Picek, B.: Classification of Cyclone Tracks over Apennines and the Adriatic Sea, Mon. Weather Rev., 136, 2210-2227, doi:10.1175/2007MWR2231.1, 2008.

Huffman, G. J., Bolvin, D. T., Nelkin, E. J., Wolff, D. B., Adler, R. F., Gu, B., Hong, Y., Bowman, K. P., and Stocker, E. F.: The TRMM Multisatellite Precipitation Analysis (TMPA): quasiglobal, multiyear, combined-sensor precipitation estimates at fine scales, J. Hydrometeorol., 8, 38-55, 2007.

Ivančan-Picek, B., Glasnović, D., and Jurčec, V.: Analysis and ALADIN prediction of a heavy precipitation event on the Eastern side of the Alps during MAP IOP5, Meteorol. Z., 12, 73-82, doi:10.1127/0941-2948/2003/0012-0103, 2003.

Ivančan-Picek, B., Glasnović, D., and Jurčec, V.: Analysis and ALADIN prediction of a heavy precipitation event on the Eastern side of the Alps during MAP IOP5, Meteorol. Z., 12, 73-82, 2003.

Ivančan-Picek, B., Horvath, K., Strelec Mahović, N., and GajićČapka, M.: Forcing mechanisms of a heavy precipitation event in the southeastern Adriatic area, Nat. Hazards, 72, 1231-1252, doi:10.1007/s11069-014-1066-y, 2014.

Jansa, A., Genoves, A., Picornell, M. A., Campins, J., Riosalido, R., and Carretero, O.: Western Mediterranean cyclones and heavy rain. Part 2: Statistical approach, Meteorol. Appl., 8, 43-56, doi:10.1017/S1350482701001049, 2001.

Jeromel, M., Malačič, V., and Rakovec, J.: Weibull distribution of bora and sirocco winds in the northern Adriatic Sea, Geofizika, 26, 85-100, 2009.

Juras, J. and Pasarić, Z.: Application of tetrachoric and polychoric correlation coefficients to forecast verification, Geofizika, 23 , 59-81, 2006.

Jurčec, V., Ivančan-Picek, B., Tutiš, V., and Vukičević, V.: Severe Adriatic jugo wind, Meteorol. Z., 5, 67-75, 1996.

Kozarić, T. and Ivančan-Picek, B.: Meteorological features of extreme precipitation in the Northern Adriatic, Croat. Met. J., 41, 53-67, 2006.

Lorenc, A. C.: Analysis methods for numerical weather prediction, Q. J. Roy. Meteor. Soc., 112, 1177-1194, doi:10.1002/qj.49711247414, 1986.

Louis, J.-F., Tiedke, M., and Geleyn, J.-F.: A short history of PBL parameterization at ECMWF, in: Proceedings from ECMWF workshop on planetary boundary layer parameterization, 25-27 November 1981, 59-79, ECMWF, Reading, UK, 1982.

Machenhauer, B. and Haugen, J. E.: Test of a spectral limited area shallow water model with time-dependent lateral boundary 
conditions and combined normal mode/semi-Lagrangian time integration schemes, Workshop on Techniques for Horizontal Discretization in Numerical Weather Prediction Models, 2-4 November 1987, ECMWF, Reading, UK, 1987.

Magaš, D.: Natural-geographic characteristics of the Boka Kotorska area as the basis of development, Geoadria, 7, 51-81, 2002.

Maiello, I., Ferretti, R., Baldini, L., Roberto, N., Picciotti, E., Gentile, S., Alberoni, P. P., and Marzano, F. S.: Multiple Doppler radar data assimilation with WRF 3d-VAR: IOP4 of HyMeX campaign retrospective studies, in: Proceedings of 8th European Conference on Radar in Meteorology and Hydrology, 15 September 2014, Garmisch-Partenkirchen, Germany, ERAD 2014 Abstract ID 042, 2014.

Manzato, A., Davolio, S., Miglietta, M. M., Pucillo, A., and Setvak, M.: 12 September 2012: A supercell outbreak in NE Italy?, Atmos. Res., 153, 98-118, doi:10.1016/j.atmosres.2014.07.019, 2015.

Mastrangelo, D., Horvath, K., Riccio, A., and Miglietta, M. M.: Mechanisms for convection development in a long-lasting heavy precipitation event over southeastern Italy, Atmos. Res., 100, 586-602, doi:10.1016/j.atmosres.2010.10.010, 2011.

Mikuš, P., Telišman Prtenjak, M., and Strelec Mahović, N.: Analysis of the convective activity and its synoptic background over Croatia, Atmos. Res., 104-105, 139-153, doi:10.1016/j.atmosres.2011.09.016, 2012.

Miglietta, M. M., Manzato, A., and Rotunno, R.: Characteristics and Predictability of a Supercell during HyMeX SOP1, Q. J. Roy. Meteor. Soc., 142, 2839-2853, doi:10.1002/qj.2872, 2016.

Noilhan, J. and Planton, S.: A Simple Parameterization of Land Surface Processes for Meteorological Models, Mon. Weather Rev., 117, 536-549, doi:10.1175/15200493(1989)117<0536:ASPOLS>2.0.CO;2, 1989.

Olsson, U.: Maximum likelihood estimation of the polychoric correlation coefficient, Psychometrika, 44, 443-460, 1979.

Orlić, M., Kuzmić, M., and Pasarić, Z.: Response of the Adriatic Sea to the bora and sirocco forcing, Cont. Shelf. Res., 14, 91116, doi:10.1016/0278-4343(94)90007-8, 1994.

Pandžić, K. and Likso, T.: Eastern Adriatic typical wind field patterns and large-scale atmospheric conditions, Int. J. Climatol., 25, 81-98, doi:10.1002/joc.1085, 2005.

Pantillon, F., Chaboureau, J.-P., and Richard, E.: Remote impact of North Atlantic hurricanes on the Mediterranean during episodes of intense rainfall in autumn 2012, Q. J. Roy. Meteor. Soc., 141, 967-978, doi:10.1002/qj.2419, 2015.

Patarčić, M., Gajić-Čapka, M., Cindrić, K., and Branković, Č.: Recent and near-future changes in precipitation-extreme indices over the Croatian Adriatic coast, Clim. Res., 61, 157-176, doi:10.3354/cr01250, 2014.

Prates, C., Richardson, D., and Sahin, C.: Final report of the PREVIEW observation Data targeting System (DTS), ECMWF, Technical Memorandum, no. 581, 2009.

Radnóti, G.: Comments on "A spectral limited-area formulation with time-dependent boundary conditions applied to the shallowwater equations", Mon. Weather Rev., 123, 3122-3123, 1995.

Rebora, N., Molini, L., Casella, E., Comellas, A., Fiori, E., Pignone, F., Siccardi, F., Silvestro, F., Tanelli, S., and Parodi, A.: Extreme Rainfall in the Mediterranean: What Can We Learn from Observations?, J. Hydrometeorol., 14, 906-922, doi:10.1175/JHM-D12-083.1, 2013.
Renko, T., Kozarić, T., and Tudor, M.: An assessment of waterspout occurrence in the Eastern Adriatic basin in 2010: Synoptic and mesoscale environment and forecasting method, Atmos. Res., 123, 71-81, doi:10.1016/j.atmosres.2012.06.018, 2012.

Ricchi, A., Miglietta, M. M., Falco, P. P., Benetazzo, A., Bonaldo, D., Bergamasco, A., Sclavo, M., and Carniel, S.: On the use of a coupled ocean-atmosphere-wave model during an extreme cold air outbreak over the Adriatic Sea, Atmos. Res., 172, 48-65, doi:10.1016/j.atmosres.2015.12.023, 2016.

Ritter, B. and Geleyn, J.-F.: A Comprehensive Radiation Scheme for Numerical Weather Prediction Models with Potential Applications in Climate Simulations, Mon. Weather Rev., 120, 303-325, doi:10.1175/1520-0493(1992)120<0303:ACRSFN>2.0.CO;2, 1992.

Robert, A.: A semi-Lagrangian and semi-implicit numerical integration scheme for the primitive equations, J. Meteorol. Soc. Jpn., 60, 319-325, 1982.

Romero, R., Doswell III, C. A., and Ramis, C.: Mesoscale numerical study of two cases of long-lived quasi-stationary convective systems over eastern Spain, Mon. Weather Rev., 128, 3731-3752, doi:10.1175/1520-0493(2001)129<3731:MNSOTC>2.0.CO;2, 2000.

Romero, R., Ramis, C., Alonso, S., Doswell III, C. A., and Stensrud, D. J.: Mesoscale model simulations of three heavy precipitation events in the western Mediterranean region, Mon. Weather Rev., 126, 1859-1881, 1998.

Rotunno, R. and Ferretti, R.: Mechanisms of Intense Alpine Rainfall, J. Atmos. Sci., 58, 1732-1749, doi:10.1175/15200469(2001)058<1732:MOIAR>2.0.CO;2, 2001.

Silvestro, F., Gabellani, S., Giannoni, F., Parodi, A., Rebora, N., Rudari, R., and Siccardi, F.: A hydrological analysis of the 4 November 2011 event in Genoa, Nat. Hazards Earth Syst. Sci., 12, 2743-2752, doi:10.5194/nhess-12-2743-2012, 2012.

Simmons, A. J. and Burridge, D. M.: An Energy and AngularMomentum Conserving Vertical Finite-Difference Scheme and Hybrid Vertical Coordinates, Mon. Weather Rev., 109, 758-766, doi:10.1175/1520-0493(1981)109<0758:AEAAMC>2.0.CO;2, 1981.

Stanešić, A.: Assimilation system at DHMZ: Development and first verification results, Croat. Met. J., 44/45, 3-17, 2011.

Stocchi, P. and Davolio, S.: Intense air-sea exchange and heavy rainfall: impact of the northern Adriatic SST, Adv. Sci. Res., 13, 712, doi:10.5194/asr-13-7-2016, 2016.

Termonia, P.: Scale-Selective Digital-Filtering Initialization, Mon. Weather Rev., 136, 5246-5255, doi:10.1175/2008MWR2606.1, 2008.

Tudor, M. and Ivatek-Šahdan, S.: The case study of bura of 1st and 3rd February 2007, Meteorol. Z., 19, 453-466, doi:10.1127/0941-2948/2010/0475, 2010.

Tudor, M. and Termonia, P.: Alternative Formulations for Incorporating Lateral Boundary Data into Limited-Area Models, Mon. Weather Rev., 138, 2867-2882, 2010.

Tudor, M., Ivatek-Šahdan, S., Stanešić, A., Horvath, K., and Bajić, A.: Forecasting weather in Croatia using ALADIN numerical weather prediction model, in: Climate Change and Regional/Local Responses, edited by: Zhang, Y. and Ray, P., InTech, Rijeka, 59-88, 2013.

Váňa, F., Bénard, P., Geleyn, J.-F., Simon, A., and Seity, Y.: SemiLagrangian advection scheme with controlled damping-an al- 
ternative way to nonlinear horizontal diffusion in a numerical weather prediction model, Q. J. Roy. Meteor. Soc., 134, 523537, doi:10.1002/qj.220, 2008.

Vrhovec, T., Gregorič, G., Rakovec, J., and Žagar, M.: Observed versus forecastedprecipitation in the South East Alps, Meteorol. Z., 10, 17-27, doi:10.1127/0941-2948/2001/0010-0017, 2001.

Wernli, H., Paulat, M., Hagen, M., and Frei, C.: SAL - A novel quality measure for the verification of quantitative precipitation forecasts, Mon. Weather Rev., 136, 4470-4487, 2008.
Wilks, D. S.: Statistical Methods in the Atmospheric Sciences, Academic Press, London, 676 pp., 2006.

Zaninović, K., Gajić-Čapka, M., Perčec Tadić, M., Vučetić, M., Milković, J., Bajić, A., Cindrić, K., Cvitan, L., Katušin, Z., Kaučić, D., Likso, T., Lončar, E., Lončar, Ž., Mihajlović, D., Pandžić, K., Patarčić, M., Srnec, L., and Vučetić, V.: Climate atlas of Croatia 1961-1990, 1971-2000, Meteorological and Hydrological Service, Zagreb , 2008. 